\title{
What is Hospitality?
}

\author{
Ramesh Raj Kunwar *
}

\begin{abstract}
This work has been fully based on review of several secondary sources, conceptual and applied discourses on hospitality education, management and research. The objective of studying this subject is to disseminate the knowledge of hospitality in the academia. Many scholars of hospitality across the world have produced different theoretical models, conceptual insights, pragmatic approaches and experiential perspectives which have become an impetus for understanding the hospitality as human phenomena, hospitality and hospitableness, the hospitality industry, its management, research, training and development as well as education in this specialized field of service and experience economy. As a purely academic discourse, the paper as a whole has been prepared by studying the origin, history, conceptualization, dimensions, interactions, typologies and neologism in hospitality. However, the present scholar could explore varying opinions on nature and functional coverage of hospitality and tourism, this study could identify many symbiotic relationships from different perspectives. It is believed that this study will serve instrumental for the learners, educators, researchers and professionals of hospitality and tourism.
\end{abstract}

Keywords: hospitality, tourism, holy trinity, typology, neologism

\section{Introduction}

What is hospitality? This question has been raised by many scholars of hospitality and tourism (Burgess, 1982; King, 1995; Jones, 1996a; Brotherton, 2013, Brotherton 1999; Ottenbacher, Harrington \& Parsa, 2009; Selwyn, 2013). More recently Jones (1996a: 6-7) has suggested that, "there is certainly no commonly shared paradigm of what we mean by 'hospitality'....Reference to the research literature would indicate that there has been little or no discussion of what we mean by hospitality.... I would propose that the idea of hospitality research exists more in form than in

\footnotetext{
Prof. Dr. Ramesh Raj Kunwar is the author of eight books on tourism and anthropology. He teaches tourism and hospitality at various universities and colleges as visiting professor. Currently he is associated with Nepal Armed Police Force (APF) Command and Staff College. He is the former Dean of Faculty of Humanities and Social Sciences, Tribhuvan University. Previously he was also the Dean of (the then) Royal Nepalese Military Academy, Kharipati, Bhaktapur., Email: kunwardr@gmail.com
} 
substance”. Also Taylor and Edgar (1996: 218, 215), in reflecting on the current state of development of hospitality research, have pointed out: "An essential first step...is to decide what the scope of hospitality research should be (and) if academic research in hospitality is to develop satisfactorily it is our view that is must do so within a coherent framework".

They have contributed significantly to establish the universal significance of these two disciplines in the present era of 'service economy' (Lashley et al., 2007) and 'experience economy' (Pine \& Gilmore,1998; see in detail Rijal \& Ghimire, 2016, pp.40-60). Due to such diverse contributions in this field, the entire specialization of hospitality and tourism has received a broader basis to form the conceptual knowledge and ideologies in these specialized disciplines. For example, Lashley and Morrison (2000) write, "Our aim has been considered with reflecting insights into the study of hospitality that encompass the commercial provision of the hospitality and the hospitality industry, yet at the same time, recognize that hospitality needs to be explored in private domestic settings... hospitality as a social phenomenon involving relationships between people." Hospitality has been considered as one of the major players of the service economy as it contributes significantly the world economy and this sector is the largest employer in the world next only to armed forces (Ottenbacher et al., 2009, p. 269). Hospitality has been one of the most pervasive metaphors within tourism studies, referring in one sense to the commercial project of the tourist industry such as hotels, catering, and tour operation, and in another sense, to the social interactions between local people and tourists, that is, hosts and guests (Germann Molz \& Gibson, 2007, p. 6).

Most of the people every where in hospitality sectors they refer to hospitality as the friendly and welcoming behavior towards the guests. Frequently, such a friendly and welcoming behavior may include sharing food, drinks and accommodation with the realm of shared happiness resulting in the establishment and maintenance of lasting relationships. In fact, the host-guest relationship serves as a power and control measure. Being a host means having an element of power over the guest, and vice-versa. In this respect, Selwyn (2000) has suggested that there is an exchange of honor and the guest signals is the acceptance of the moral authority of the host. Cole (2007) has attempted to discuss how hosting and rituals serve in domesticating and controlling the strangers who penetrate the circle of the host home, hearth and social world (p. 720). The hosts have control over the guests as they develop a dependency postulate resulting in relationships lasting for life.

The view of hospitality has been supported by the arguments that it involves complex relationships between providers and receivers in the locations of service experienced (Di Domenico, \& Lynch, 2007; Lashley, Lynch \& Morrison, 2007; Lugosi, $2008,2009)$. In these all discourses, the scholars tend to agree that beyond food, drink 
and accommodation, hospitality transactions involve the interpretation, articulation and negotiation of identities, power relationships, property relations and space.

The contemporary hospitality industry is both multivalent and enormous as people would argue the modern market based, commercial hospitality has 'democratized', the practice of hospitality marketing it more 'egalitarian' in the sense that we are all free to enter the market and buy whatever hospitality we want, wherever and to what extent we want or consume it, Selwyn (2013) has argued. This scholar is of the opinion that basic function of hospitality is to establish new relationships or to promote already existing ones and it is achieved while making exchanges -- both material and symbolic -- between hosts and guests (Selwyn, 2000, p.19).

On the other hand, Douglas (1987; cited in Lugosi, 2009, p. 398) has come up with an anthropological approach to define the alternative prospective on hospitality and hospitable behavior, which is quite similar to the works of Selwyn (2000) where this scholar has argued that hospitality is a particular type of social practice in which exchanges of goods and services, both material and symbolic are used to establish new relationships or build existing ones. Truly hospitable behavior has a concern for providing hospitality by entertaining, protecting and securing guests, added Ritzer (2007). Another scholar has added that hospitable behavior is one dimension and certain physical products (food, drink and accommodation) constitute the other dimension of the service exchanges and it has other two dimensions too -- spatial dimension occurs within a physical location or place and temporal dimension is manifested in types of occasion the service has been rendered (Brotherton, 2013, p. 61).

A scholar has claimed that expectations, rules and resources exist for both host and guest while performing the roles of 'good host' and 'good guest', both the sides being contractually obligated and responsible to each other (Zlomislic, 2004). This scholar has further added that hospitality is the name for providers' relation to the receivers, all transacted, ethically however it may go beyond invitation. Sometimes, the providers may remain unprepared or prepared to be unprepared for the unexpected arrival of guests. On top of all, hospitality is all about receiving or welcoming beyond the concept of power, protocol or law. It is an opening without the horizon of expectation where peace can be found beyond the confines of conflict. In this respect, Caputo (1997, cited in Germann Molz \& Gibson, 2007) has explained that when the host says to the guest, "Make yourself at home", this is a self-limiting invitation. "Make yourself at home", means please feel at home, act as if you were at home, but remember, that is not true, this is not your home but mine. This reveals that hospitality is being offered on temporary basis and it is quite similar with the notion of tourism.

The focus of study in hospitality has shifted from simply the thematic 
investigation of management of guest and host to as a significant means of exploring and understanding the society. Many scholars have recognized that the academia in management offers a utilitarian conception of hospitality which has been widely criticized for its failure to address the social, cultural, political and emotional dimensions of such transactions (Lashley et al., 2007; Lugosi, 2008, 2009). Nevertheless, managerial concerns about the organization of service environment and mobilization of resources are fundamental to the understanding of commercial operations exchanging food, drink or shelter and host-guest interactions.

Other contributions of this field add that hospitality, as an art and science embedded with welcoming gesture is manifested in offers of shelter, food, and drink, combined with various levels of social interaction, which emerge in private, social or commercial settings (Brotherton, 1999). Such transactions involve performances of self and the reproduction of established social and cultural norms, but hospitality may enable the construction of new alternative forms of sociality (Bell, 2007; Lugosi, 2009). Hospitality has a physical dimension -- the body is central to its production, for example, in the preparation of food or drink or in the gestures that come to embody hospitableness, and the multi-sensuality of food and drink places the body centrally within its consumption. There is also a broader materiality to hospitality alongside food and drinks, paraphernalia such as crockery, cutlery, drinking vessels, furnishings, microwaves, kettles or cold-water dispensers shape social practice (Lugosi, 2014).

A central theme shared between tourism studies explores encounters between people who are "strangers" to each other. This encounter involves the movements of a mobile actor (the guest) into the home territory of a static host (Bell, 2009). From a hospitality subject perspective, the seeds were first sown in discussions that informed In Search of Hospitality edited by Conrad Lashley and Alison Morrison in 2000. This gave birth to several other hospitality literatures such as, Hospitality A Social Lens edited by C. Lashley, P. Lynch and A. Morrison (2007), Mobilizing Hospitality edited by J. Germann Molz and S. Gibson (2007), The Sage Handbook of Hospitality Management edited by B. Brotherton and R.C. Wood (2008), The Origins of Hospitality and Tourism written by K. D. O'Gorman (2010), Extending Hospitality: Giving Space, Taking Time edited by Dikeç Mustafa, N. Clarke and C. Barnett (2009), Gary Alan Fine's (2008) Kitchens: The Culture of Restaurant Work (update with new preface), and Key Concepts in Hospitality Management edited by R.C. Wood (2013). All these literatures have shown that hospitality itself is the object of the study and the other scholars who are from different disciplines such as cultural theory, geography, anthropology, sociology, philosophy, theology, linguistics, applied business and management who have made significant contributions to advancing the understanding hospitality in commercial and non-commercial sector.

According to Lashley and Morrison (2000), hospitality requires the guest to feel 
that the host is being hospitable through feelings of generosity, a desire to please and a genuine regard for the guest as an individual. Hospitality is therefore more than just about the host providing food and accommodation to the guest but also about entertaining the guest. Entertaining is a good way to be friendly because it involves the offer of a degree of intimacy, a share in the host home life. This motive, as well as duty, can lead people to entertain those with whom their connection is essentially official; it is as if they were saying, 'Let's not be merely business partners, we are human beings as well' (Telfer, 2000). 'Entertainment', originally refers to plays, music, dancing or masks provided for the 'guests' enjoyment, but later became synonymous with hospitality as it is today (American Heritage Dictionary, 1982; cited in King, 1995 , p. 223). The roots of the word entertain mean a holding together, as in "the human glue" holding together the social order.

Hospitality is vital in the services marketing context because it is the "service enhancer" which would help providing added value to their core service provisions. Eventually, this would lead to high level of customer satisfaction with the overall services. Despite the importance of hospitality in creating "memorable staying experiences" for hotel guests, there has been no reliable and valid measure that can be used to evaluate the level of their foreign counterparts with respect to their levels of expectations hotel hospitality.

\section{Origin of Hospitality}

The etymological roots of the term hospitality where identified as being Medieval Latin "hospes" (guests); "hospitari" (be a guest); and "hospitabilis" (put up as a guest; American Heritage Dictionary, 2007; cited in Ottenbacher et al., 2009, p. 265). All modern words readily associated with hospitality are evolved from the same hypothetical Proto-Indo-European root ${ }^{*}$ ghos- $t i$ which means stranger, guest and the host is someone with whom one has reciprocal duties of hospitality (American Heritage Dictionary, 2001; cited in O'Gorman, 2007, pp. 17-18). The word guest came from the Middle English gest, evolved from Old Norse gestr, and from Old High German gast, both come from Germanic ${ }^{\star}$ gastiz. ${ }^{\star}$ Ghos- $t$ i also evolved to the Latin roots hostis, enemy, army, where host (multitude) and hostile find their origin; hostia, sacrifice, host (eucharistic). The combination of ${ }^{*} g h o s-t i$ and another Proto-IndoEuropean root ${ }^{*}$ poti powerful, gave the compound root ${ }^{*}$ ghos-pot-, ${ }^{*} g h o s-p o(d)$-, which evolved to the Latin hospes and eventually into hospice, hospitable, hospital, hospitality, host (giver of hospitality), hostage, and hostel. The Greek languages also evolved from the same Proto-Indo-European base, ${ }^{\star}$ ghos-ti gave the Greek xenos which has the interchangeable meaning guests, host, or stranger. Traditionally, the guest is the person with whom one has mutual obligation of hospitality. A guest is also a stranger, and a stranger could well be hostile. Strangers are feared because their intentions are often unknown and they can appear as bearers of magical and/ 
or mystical powers. The law or customs pertaining to the Ancient Greeks of offering protection and hospitality to strangers is philoxeno. Literally 'love of strangers' is the antithesis which is still in common English usage today in xenophobia (O'Gorman, 2007, pp. 17-18).

The literatures of hospitality show that hospitality implied a reciprocal relationship which imposed certain obligations on the guest. Browner, as cited by Santich (2007) has suggested that the Anglo - European world has adopted not only the Latin word, but also the Latin concept of hospitality rather than the ancient Greek concept (Browner, 2003; cited in Santich, 2007). 'Hospitalitas' in Latin means the entertainment of guests, or hospitableness (Glare, 1973; cited in Santich, 2007). It is derived from the word 'hospes' meaning either host or guest-guest in the sense of visitor of friend, someone with whom the host has some ties and not necessarily a complete stranger. In ancient Greek, hospitality is translated as 'xenia', derived from 'xenos', meaning host or guest but more particularly a stranger, wanderer, refuge, foreigner (Liddell, \& Scott, 1983; cited in Santich, 2007). On the basis of this, Browner has hypothesized that the Greek concept of hospitality is based on the primacy of the guest (the obligation towards strangers), whereas the Latin concept which we have inherited is based on the primacy of the host. 'In the West, it is the role of the host the matters, for he is the lord of strangers' (Browner, 2003, cited in Santich, 2007, p. 51).

The commandment of religious bodies, the care of the sick, the desire to display wealth, exchange goods and hear the news were all factors promoting hospitality. Religious obligations and Christian institutions were prominent in the Middle Ages, providing hospitality through hospices and monasteries. The term 'Hospitallers' was first applied to those whose duty it was to provide hospitum (lodging and entertainment) for pilgrims (Selwyn, 2000, p. 24). The most noted institution of its order called Knights Hospitallers, or Knights of St. John at Jerusalem, following the 1099 crusade (Burgess, 1982, p. 54-55). The Crusades consisted of several military expeditions between 1095 and 1291 in which Christian powers attempted for regain the Holy land from the Muslims (Fridgen, 1996:11). According to Ottenbacher et al. (2009), The Knights Hospitaller is a charitable order...consisting of military monks funded circa $1048 \mathrm{CE}$ in some hospitals in Medieval Europe. Later on, they moved to the island of Rhodes, and finally to Malta, establishing hospitals and hospices in addition to fighting to defend and strengthen Christian interest. From the historical context, thousands of pilgrims travelling to the holy places often expected the Knights to protect and provide shelter throughout the journey (Partner, 1982; Ottenbacher et al., 2009, p. 265). Hence, hospitality would appear to be a rather broad multidimensional construct that extends beyond basic food and the shelter.

According to Nailon (1982, p. 137), the historical development of hospitality has been summarized by Borer (1972), Taylor and Bush (1974) and Taylor (1977) for the 
United Kingdom and by White (1968) for the United States. What emerges from the literature has been summarized in Christian (1979; cited in Nailon, 1982, p. 137) as, 'Hospitality throughout history has been centered around security, physical comfort and psychological comfort [provided] to other by a host' (Nailon, 1982, p. 137). Throughout the world, commercial hospitality has developed in step with expanding facilities for travel. First, the caravans following trading routes, then the stage coaches followed by the railways and, more recently, travel by motor cars and air. The modern hotel, originally established for nobility travelling in Europe, originated from the hotel garni (rented elegant apartments) at the beginning of the last century (Medlik, 1972; cited in Nailon, 1982, p. 136).

Hospitality is not only defined just by its purity but also by its impurities. These impurities referred variously to as the 'strain of hospitality' has been explored by authors such as Ryan (1991), Mathieson and Wall (1982) and Smith and Brent (2001) in their works on social and cultural dimensions of tourism and hospitality. These scholars extend to social constructs that determine host-guest-relations including those of xenophobia and neo-colonialism. The role of cultural arrogance and displays of this by both hosts and guests provide a strong argument for the inversion that occurs in the hospitality encounter/ experience of modern times (Sheringham \& Daruwalla, 2007).

\section{Conceptualization of Hospitality}

Classic definitions of hospitality suggest it as a social phenomenon with roots in societies extending through thousands of years (O'Gorman, 2005; cited in Ritzer, 2007). The semantic definitions include those in dictionaries, thus hospitality is the 'friendly and generous reception and entertainment of guest and strangers' (Oxford Quick Reference Dictionary, 1996) or 'kindness in welcoming strangers or guests' (Collins Concise English Dictionary Plus, 1989). Variant terms, such as the word 'hospitable' is defined in The Oxford English Dictionary (1970) in very similar terms to 'hospitality' as 'offering or affording welcome and entertainment to strangers ... of persons ... of things, feelings, qualities etc ... Disposed to receive or welcome kindly, open and generous in mind or disposition. Hospitality operates on knife edge, embodying its etymological origins, viz. Latin hospes, meaning friend as well as enemy (Visser, 1991). Jochelson (1926; cited in Burgess, 1982, p. 50) observed 'Hospitality often turns enemies into friends and strengthens the amicable relations between groups foreign to one another'.

The hospitality elements may be represented conceptually as a package. An even more elaborate presentation is made by Burgess (1982), who has observed the concept as five points -- Service, Beverage, Accommodation, Entertainment and Food, within a sphere of psychological and physiological comfort and security, which is itself 
contained by a sphere of hospitable and social interaction. A full description of this concept is given in Burgess (1982, p. 50) that, 'The outer, primary interacting element is that of the social relationship fostered by the warm, friendly, welcoming, courteous, open, generous behavior of the host, creating the hospitable social environment. This supports and promotes the positive feeling of security and comfort created by the physical structure, design, décor and location of the facility. Finally, the provision of accommodation facilities to sleep, eat, relax and wash, together with the supply of food, beverage, service and entertainment.'

According to Muhlmann (1932), hospitality represents a kind of guarantee or reciprocity one protects the stranger in order to be protected from him. This approach is closer to the ancient Greek concept of philoxenos (love of strangers) and its antithesis of which is still in common English usage today: xenophobia ("a fear of foreigner or stranger").

Many gift exchanges and hospitality events today establish similar symbolic bonds. The concept of symbolism is that we live in a social reality where things, people, words, situations and actions are social objects used for representation and communication. They are given meaning not by nature but by communities and become understood and transmitted by experience and language. Symbols are central to human social life in enabling people to learn, understand, communicate and enjoy a satisfying relationship beyond more animal response (Burgess, 1982).

So far as evidential definitions of hospitality are concerned, those will precisely arise from efforts to understand, interpret and utilize existing diverse documentary source on hospitality to inform definitional processes in terms of theory building, or more precisely in term of providing theoretical context. The evidential approach is thus rooted in academic literature and seeks to locate and define hospitality within the 'real world' of evidence. Nevertheless, attempts at the evidential definition of hospitality provide a bridgehead into consideration of the theoretical sources that have thus far come to inform research in the field (Brotherton \& Wood, 2008).

Hepple, Kipps and Thompson (1990) have argued that hospitality consists of four basic characteristics. Firstly, hospitality is behavior confessed by a host or a guest who is away from home. Secondly, it is interactive in nature and involves personal contact between the provider and receiver. Thirdly hospitality comprises of a blend of a tangible and intangible factors. Finally, the host provides for the guest's security, psychological and physiological comfort.

Tideman (1983; cited in Brotherton \& Wood, 2008; cited in Brotherton, 1999, p. 266) has made an observation that hospitality is the method of production by which the needs of the proposed guest are satisfied to the utmost and that means a supply of goods and services in a quantity and quality desired by the guest and at a price 
that is acceptable to him so that he feels the product is worth price - a definition that could be a description of almost any economic activity. This has been elaborated by some scholars like Bell (2007, p. 91),van Keken and Go (2006, p. 58) and Wharton (2007. p.111) have coined the term as 'night time economy', 'entertainment economy' and 'repetitive economy' respectively. In the same vein, Pfeirfer (1983; cited in Brotherton, 1999, p. 267) has also put forward a definition of hospitality from a strongly supply-side economic perspective; Hospitality consists of offering food, beverage and lodging, or, in other words, of offering basic needs for the person away from home. Jones (1996; cited in Brotherton \& Wood, 2008; Brotherton, 1999, p. 267) has argued that hospitality is made up of two distinct services - the provision of overnight accommodation for people staying away from home, and the provision of sustenance for people eating away from home.

Cassee (1983; cited in Brotherton \& Wood, 2000) has defined hospitality as a harmonious mixture of tangible and intangible components - food beverages, beds, ambience and environment, and behavior of staff. Later on, this definition has been slightly modified by Cassee and Reuland (1983) to a harmonious mixture of food, beverage and/or shelter, a physical environment, and the behavior and attitude of people. These definitions speak about the creation of hospitality industry and: consumption (Brotherton, \& Wood, 2008).

According to Reuland et al. (1985:142), when a guest comes into contact with an organization offering something like hospitality, three elements in the hospitality process, which we describe as situations, can be distinguished. They can be represented by three circles.

The three circles represent the following situations:

1) The situation of the Provider (Pr); this is the situation of the restaurant/hotel, who realizes the direct contact with the consumer. The situation is controlled by the instructions the waiter has been given by his chief, but is also influenced by his own norms and standards and his (changing) temper.

2) The situation of the Receiver ( $\mathrm{Re})$; the guest enters the restaurant or hotel bringing with him his own background and ideas.

3) The situation of the Transfer ( $\mathrm{Tr}$ ); in this situation, created by both the Provider and the Receiver, the Transfer of hospitality is realized. This situation starts when the Receiver comes under the roof of the Provider of hospitality.

In conclusion Reuland et al. (1985, p.146) suggest that good planning and adequate (cultural) management are essential tools to prevent the cultural clash and to find such a solution that hospitality offer and expectations are in harmony without disturbing the cultural differences. 
The act of hospitality involves 'an action (a welcome), an attitude (the opening of oneself to the face of another... and the opening of one's door and the offering of the space of one's house to a stranger), and a principle (disinterestedness)' (Jelloun, 1999). Telfer (2000) has associated hospitality not just with pleasing others but also with the reciprocal motives of hoping to have the hospitality returned where the host also seeks to benefit. Understanding hospitality refers to the understanding of the dynamics in spaces of hospitality. M. Dikec (2002) has prioritized the opening of the boundaries and giving space to the stranger for mutual recognition. These spaces can be social, cultural, institutional, ethical and political where participants and engage with and learn from one another. This opening of spaces, however, requires regulating hospitality situations (Friese, 2004) in order to facilitate more enriching hospitality experiences (Grit, 2004; in Lynch et al., 2011).

However, what Burgess(1982), Cassee and Reuland (1983) and Hepple et al. (1990) have in common is their failure to adequately define hospitality per se. In common with others, for example King(1995).They confuse hospitable behavior, or hospitableness, with hospitality and fall into the trap of suggesting that one of the important features of hospitality is making the guest "feel at home"(Brotherton, 1999:167).The nature and importance of the distinction between hospitableness and hospitality will be addressed.

Brotherton's (1999) definition of hospitality reflects a different perspective. But this has been developed from evidence perspective. In his view, hospitality is "a contemporaneous human exchange, which is voluntarily entered into , and designed to enhance the mutual well-being of the parties concerned through the provision of accommodation, and / or food, and /or drink" (p. 268) This interpretation emphasizes the exchange relationship, the process- giving and receiving, with the attendant benefits and obligations. The phrase to enhance mutual well- being of the parties concerned' refers both to the happiness of the guest and the inherent reciprocity in the exchange (Santich, 2007). However, this relatively narrow definition has now been challenged on a number of grounds (Lynch et al., 2011). Lugosi (2014) has commented that firstly it stresses mutual well-being which ignores asymmetries of power and the potentially oppressive nature of hospitality transactions. Secondly, because of its managerial underpinnings, it focuses narrowly on provision which does not address the importance of transactions, particularly issues surrounding reward, compensation and reciprocity. Thirdly, it ignores the importance of social interaction in hospitality and finally, its places excessive emphasis on food and drink.

Morrison and O'Gorman (2006) have offered the following more multifaceted definition: 'It represents a host's cordial reception, welcome and entertainment of 
guests or strangers of diverse social backgrounds and cultures charitably, socially or commercially with kind and generous liberality, into one's space to dine and/or lodge temporarily. Dependent on circumstance and context the degree to which the hospitality offering is conditional or unconditional may very' (Lashley, Lynch, \& Morrison, 2007). Hospitality has been commonly defined as something related to the friendliness, kindness and hospitableness (Thio, 2005).

Jones (1996) has suggested that there is certainly no commonly shared paradigm of what we mean by 'hospitality' Reference to the research literature would indicate that there has been little or no discussion of what we mean by hospitality. Also Taylor and Edgar (1996), in reflecting on the current state of development of hospitality research, have pointed out that an essential first step is to decide what the scope of hospitality research should be, and if academic research in hospitality is to develop satisfactorily it is our view that is must do so within a coherent framework.

\section{Hospitality: Three Domain Approach}

For the first time in the history of hospitality studies, Lashley (2000) developed three domain approach, which are social (pp. 5-10), private(pp.10-12), and commercial (pp.12-15). The effort of developing these three domains is aimed to establish a width of definition of hospitality. Social hospitality can be defined as the social setting in which hospitality and acts of hospitableness takes place together with the impacts of social forces on the production and consumption of food, drink and accommodation (Thio, 2005).

Certainly, there are important lessons to be learnt from the study of the social and cultural domain of hospitality. First, different societies will have degrees of culturally defined obligations to be hospitable. Some cultures will require individuals to meet certain levels of expectation to offer hospitality to strangers. Thus, different societies will be more or less predisposed to be hospitable to the stranger/tourist. Second, obligations to offer hospitality to strangers changes over time. Increased contact with visitors appears, particularly in commercial tourist contexts, to change obligations to be hospitable. Familiarity, it seems, can breed contempt. Thirdly, it is possible to reintroduce frontline hospitality and tourist staff to these obligations to be hospitable through training and management practice (Lashley et al., 2007, pp.7-8).

According to Lashley, the inclusion of the social domain enables the understanding of social settings in which acts of hospitality and acts of hospitableness take place together with the impacts of social forces on the production and consumption of food/ drink/ and accommodation (Lashley \& Morrison, 2000). Additionally, the social domain will rekindle the notion that in ancient, subsistence cultures, 'beliefs about hospitability and obligations to others were located in views and visions about the nature of society and the natural order of things. So, social hospitality can be defined 
as the social setting in which hospitality and acts of hospitableness take place together with the impacts of social forces on the production and consumption of food, drink and accommodation (Thio, 2005). Social Hospitality means observing hospitality in a boarder social context (Lashley \& Morrison, 2007). Furthermore, Lashley (2000) has stated that the social context has an important role in the cultivation/ production, distribution, preparation, and consumption of food and beverage because food habits are culturally formed. In other words, in different cultures, there are different sets of rules to be performed. For instance, in a typical wedding party, the food, decoration and wedding dress are chosen to fit with the culture of the host.

The majority of social hospitality is provided on an occasional basis, on a fairly small scale, and by the host or hostess themselves probably in their own home. In this way each social hospitality experience would be a unique experience, which would be customized or personalized for each guest. The commercial hospitality operation would be a comparatively large scale (Lockwood \& Jones, 2000, p. 161). Social hospitality is essential supply led. It is the host or hostess who invites their guests to stay for the weekend or to pop round for supper or who decides the food to cook and the drink to serve. On the other hand, commercial hospitality is largely demand led. It is customer's decision as to where and when they are going to stay or what they are going to eat or drink. This gives the customer a greater degree of choice of and greater degree of control over the hospitality experience to which the commercial hospitality provider must be able to respond. The private domain influences the more writtenabout commercial domain of hospitality. Expectations formed in the home shape guest demands outside of the home. The provision of in-room facilities can be seen as satisfying these home-learned expectations.

Drawing on another perspective, many hospitality businesses are themselves 'commercial homes' (Lynch \& MacWhannell, 2000). Commercial homes (Lynch, 2005) in guest houses, bed and breakfasts establishments, farm-stay properties and small hotels in particular involve guests staying in the same dwelling as the host. Lynch and MacWhannell provide a useful model for understanding the relationships between paying guests and hosts depending on the degree to which they share domestic private space. Although the interface between resident guest and host is at their sharpest in the accommodation sector, pubs, inns and bars, and some restaurant and cafe businesses have close links between the home and the commercial activity. Many of these quasi-commercial firms can be described by the label 'lifestyle', run by people who want to have more control of their lives, or who 'like the life', and 'make a reasonable' living. Often the domestic setting is seen as 'not having to work', or presents a business opportunity where their life skills, learnt in the home provide them with an opportunity to 'work at home' (Lashley, \& Rowson, 2005; cited in Lashley et al., 2007). The overlap between the commercial provision within a domestic setting, 
being paid to provide hospitality, is at the heart of the operator's dreams.

The private domain of hospitality has provided the source to some interesting studies over recent years. On one level, the domestic environment is an important arena for learning about receiving guests and the obligations of the host. Half the accounts of 'special meal occasions' (Lashley et al., 2005) were located in domestic settings, and the language of domestic hospitality was used to evaluate hospitality in commercial settings, 'they made me feel at home' for example, O’Mahony's (2003; cited in Lashley et al., 2007) has studied the profile of five leading restaurateurs in Australia and suggested that learning about food and dining in the home was a common source of motivation. In some cases, learning to cook with a mother or grand-mother was an important source of skill. In other cases, the experience of food and drink, and hosting, provided a source of inspiration that became invaluable when they entered the restaurant business (Lashley et al., 2007).

The commercial domain of the hospitality literature is more specific in its definition. Cassee sees hospitality as a harmonious mixture of tangible and intangible components- food, beverages, beds, ambience and environment, and behavior of staff' (Brotherton, 1999). This definition has been since modified to a 'harmonious mixture of food, beverage and/or shelter, a physical environment, and the behavior and attitude of people. According to King (1995), commercial hospitality is 'a specific kind of relationship between a host and a guest in which the host understands what would give pleasure to the guests and enhance his or her comfort and well-being and deliver it generously and flawlessly in face to face interaction'. In the commercial context the obligation to provide hospitality services is critically more important if the organization's service mission is to create "memorable experiences" (Ariffin et al., 2011, p.341). Hemmington (2007, cited in Ariffin et al., 2011) identified five key dimensions of commercial hospitality as host-guest relationship, generosity, theatre and performance, lots of little surprises and safety and safety and security. Lashley et al. (2005; cited in Ariffin et al., 2011) revealed that emotional aspects were found to be much more influential than the quality of the food in creating memorable dining experiences.

Telfer (2000) has claimed that commercial hospitality need not be inevitably inhospitable, there are many examples of those managing hotels, pubs, coffee shops, and restaurants who provide generous and warm feelings among their clients because they recognize the key importance of customer experiences, and the need for these to be genuinely felt. Conversely, Ritzer has made a powerful criticism of corporate providers who ultimately prioritise shareholder interests above those of guests/ customers, employees, and other stakeholders (Lashley et al., 2007, p. 9). 
However, commercial domain is clearly influenced by above mentioned social and cultural, and private or domestic domains of hospitality. It is important that those studying hospitality recognize the interplay of both the cultural and domestic on the commercial provision of hospitality. It is also vital that commercial providers develop a more subtle understanding of hospitality so as to focus on building long-term customer relationships. Successful hosts are able to engage customers on an emotional and personal level, which creates feelings of friendship and loyalty among guests (Lashley \& Morrison, 2003).In course of analyzing hospitality, Lockwood \& Jones (2000, p.161) have authentically differentiated between social hospitality and the commercial hospitality which they have portrayed in the figure given below. This differentiation will make clear to understand social and commercial hospitality in better way.

\begin{tabular}{|l|l|}
\hline Social hospitality & Commercial hospitality \\
\hline Supply led & Demand led \\
\hline Occasional & Continuous \\
\hline Small scale & Large scale \\
\hline Self-administered & Administered by others \\
\hline Non-dedicated facilities & Dedicated facilities \\
\hline Unique experience & Repeatable experience \\
\hline Personalized activity & Economies of scale \\
\hline Social experience & Service experience \\
\hline Not for profit & Financial sustainability \\
\hline
\end{tabular}

Comparing social and commercial hospitality (Lockwood \& Jones, 2000, p.161).

One immediate weakness which emerges from a cursory look at the list of contributors is the overwhelmingly UK- Eurocentric focused nature of the authors and their research. This should be really have been sub-titled 'A UK Perspective' since North America, Asia-Pacific and Australasia are weakly represented with the exception of Ritzer's McDonaldization of society thesis which North American (Page, 2003, p. 726).

\section{Hospitality A Social Lens}

This is another innovation of hospitality research and studies invented by Lashley et al. (2007). In course of defining, describing and analyzing this concept Lashley et al.(2007) write, in broader social science research, hospitality as a social phenomenon has been inferior, marginalized and less heard. A conceptual development is the social lens framework where the host-guest relationship is located at the core of hospitality. The meaning of the host-guest relationship depends on the socio-cultural context. The hospitality social lens (Lashley et al., 2007) explains wider relationships within 
society, arguably looking at social relationship from an entirely different perspective. It argues that the host-guest relationship is multi-dimensional and that hospitality can be observed "as a mirror that reflects social norms, values, beliefs and ideologies" (p.173). Dominant themes in explaining a host-guest transaction through a social lens include a three-layered approach: first, commercial and domestic discourses, second, dimensions of inclusion and exclusion, politics of space types and sites, and laws and the third maps out of socio-cultural context (Causevic, \& Lynch, 2009). While summarizing the whole works of the book Lashley et al. (2007) have proposed nine robust themes of hospitality, the dominant one being hospitality as human phenomenon (the nexus is the host/guest transaction) followed by domestic discourse, commerce inclusion and exclusion, laws, performance, politics of space, types and sites and social and cultural dimension, all they form a hospitality conceptual lens.

Table 1: Hospitality social lens summary of themes

\begin{tabular}{|l|l|}
\hline $\begin{array}{l}\text { Host/Guest } \\
\text { transaction }\end{array}$ & $\begin{array}{l}\text { In some cases the role of authority is accepted by the hosts in } \\
\text { other cases, the role of authority is not accepted. }\end{array}$ \\
\hline $\begin{array}{l}\text { Inclusion/ } \\
\text { Exclusion }\end{array}$ & $\begin{array}{l}\text { Certain strangers are welcomed and transformed into guests, } \\
\text { certain strangers are not welcomed. }\end{array}$ \\
\hline Laws & $\begin{array}{l}\text { Standards norms, principles and obligations defined though } \\
\text { the social and cultural settings. }\end{array}$ \\
\hline Performance & $\begin{array}{l}\text { Symbolism of meaning authenticity and staged authenticity, } \\
\text { depicted through the host guest transaction. }\end{array}$ \\
\hline $\begin{array}{l}\text { Domestic } \\
\text { discourse }\end{array}$ & $\begin{array}{l}\text { Domestic settings, gender issues and practices observed } \\
\text { through the transaction between the host and the guest. }\end{array}$ \\
\hline Politics of space & $\begin{array}{l}\text { Boundaries which denote inclusion and exclusion, domestic } \\
\text { and commercial discourses. }\end{array}$ \\
\hline Types and sites & $\begin{array}{l}\text { Forms and locations and their role in experiencing the host/ } \\
\text { guest transactions as the core of the hospitality. }\end{array}$ \\
\hline Commerce & $\begin{array}{l}\text { Commercial hospitality is only one among other social } \\
\text { Dimensions of host/guest transaction. }\end{array}$ \\
\hline $\begin{array}{l}\text { Socio-cultural } \\
\text { dimension }\end{array}$ & $\begin{array}{l}\text { Certain norms are constructed through the relationship } \\
\text { between the host and the guests and the socio-cultural } \\
\text { contexts under which the relationship take place. }\end{array}$ \\
\hline
\end{tabular}

Source: Causevic, \& Lynch (2009:126).

Table 2: Concepts of hospitality from hospitality: a social lens

\begin{tabular}{|l|l|l|}
\hline Perspective & Concepts of Hospitality & Author \\
\hline
\end{tabular}




\begin{tabular}{|c|c|c|}
\hline Anthropology & $\begin{array}{l}\text { Moral obligations defining social and cultural } \\
\text { expectations about behavior as host guest intra- } \\
\text { tribal hospitality and reciprocity }\end{array}$ & Cole \\
\hline Architecture & $\begin{array}{l}\text { Hotel space designed to create an ambience } \\
\text { of hospitality experiences-symbolism and } \\
\text { the rhetoric of hospitality adapts to address } \\
\text { developments in consumer expectations }\end{array}$ & Wharton \\
\hline Classics & $\begin{array}{l}\text { Historical insight into religious and cultural } \\
\text { obligations for hosts and guest in Greek, Roman } \\
\text { and early Christian setting }\end{array}$ & O'Gorman \\
\hline Culture & $\begin{array}{l}\text { Ethical hospitality-differences between powerful } \\
\text { hosts and vulnerable guest-the widespread fear of } \\
\text { global strangers }\end{array}$ & $\begin{array}{l}\text { Sheringham } \\
\text { and } \\
\text { Daruwalla }\end{array}$ \\
\hline $\begin{array}{l}\text { Cultural } \\
\text { Geography }\end{array}$ & $\begin{array}{l}\text { Use of bars, restaurants, clubs and boutique } \\
\text { hotels in the regeneration of city centre space- } \\
\text { role of hospitality experiences in establishing and } \\
\text { reinforcing lifestyle experiences. }\end{array}$ & Bell \\
\hline Gastronomy & $\begin{array}{l}\text { Eating and drinking as focus of gastronomy- } \\
\text { reflection on the acts of hosting and the manners } \\
\text { of being guests }\end{array}$ & Santich \\
\hline History & $\begin{array}{l}\text { Multicultural evolution of the 'hospitality } \\
\text { industry' in the various colonial hotels and pubs } \\
\text { of Melbourne in the nineteenth century }\end{array}$ & O’Mahony \\
\hline $\begin{array}{l}\text { Human } \\
\text { Resource } \\
\text { Management }\end{array}$ & $\begin{array}{l}\text { Commercial control through looking good and } \\
\text { sounding right-hospitality experiences require } \\
\text { selection and development of service staff who } \\
\text { sound and look the 'part' as defined by the brand } \\
\text { and the market it is supposedly servicing }\end{array}$ & $\begin{array}{l}\text { Nickson and } \\
\text { Warhurst }\end{array}$ \\
\hline $\begin{array}{l}\text { Socio- } \\
\text { linguistics }\end{array}$ & $\begin{array}{l}\text { Demonstrating how fast food restaurants } \\
\text { manufacture, control and process customers in } \\
\text { a set of predicable processes shaping customer } \\
\text { tastes and expectations supporting Ritzer's theory }\end{array}$ & $\begin{array}{l}\text { Robinson } \\
\text { and Lynch }\end{array}$ \\
\hline Sociology & $\begin{array}{l}\text { Commercial home of the micro-business being } \\
\text { operated as a guest house of hotel-represent a } \\
\text { forum for both private and commercial acts of } \\
\text { hospitality }\end{array}$ & $\begin{array}{l}\text { Di Dimenico } \\
\text { and Lynch }\end{array}$ \\
\hline
\end{tabular}




\begin{tabular}{|l|l|l|}
\hline Sociology & $\begin{array}{l}\text { Component parts of the theory of } \\
\text { McDonaldization are an anathema to spontaneous } \\
\text { hospitable behavior }\end{array}$ & Ritzer \\
\hline
\end{tabular}

Source: O'Gorman (2010, p. 4).

Later on, in course of theorizing hospitality, Lynch et al. (2011) have proposed twelve different new areas of hospitality research which are: historical approaches to hospitality, narrative hospitality, relationship between hospitality and immobility, cartographies and specialties of hospitality and virtuality, hostipitality, ethics and politics of hospitality, embodied hospitality, hospitality and materiality, researching hospitality and inclusive hospitality.

\section{Dimensions of Hospitality}

The literatures have highlighted that hospitality is multilayered phenomena (Lugosi, 2009). Hospitality is also multi-interpretable concept (Munsters, 2010). According to Selwyn (2013), hospitality is multivalent and enormous. Hospitality demonstrates that managerial, social scientific and philosophical approaches offer a partial but important understanding of its different forms and dimensions. To understand how it is social and commercial manifestation between the different approaches to hospitality: the managerial or operational focus on how food and drink provision emerges as a set of proposition for customers, the anthropological focus on the social and cultural functions of hospitality transactions, and the philosophical concerns about the ethical or historical principles that underpin and shape these transactions (Lugosi, 2009).

Among the various scholars of hospitality, Brotherton (2003), O'Gorman (2007) and Lashley et al. (2007) have developed the dimensions of hospitality which have become the impetus for understanding hospitality in better way. According to Brotherton (2003), the concept of hospitality involves an identification of where, why and when hospitality occurs and what is included in it. This gives rise to four dimensions:

The spatial dimension deals with the where aspect and facilities exploration of the locations and places hospitality takes place.

The behavioral dimension is concerned with the why aspect and concentrates attention on the motives lying behind the provision of and the human processes involved in its delivery.

The temporal dimension focuses on the when aspect or the incidence of hospitality. This is essentially concerned with the notion of hospitality occasions.

The physical dimension identifies the physical features and products associated with any given type of hospitality provision. 
The combination or aggregation of these four dimensions constitutes the concept of hospitality as, in total, they comprise all components of any given 'hospitality situation. Therefore, they can be used, individually or collectively.

In addition to this, it is clear that a consideration of one or more of these dimensions could be used as a vehicle to analyze hospitality chains and developments in the industry. For example, combinations of these dimensions could be used as a basis to establish the existence of strategic groups within the industry. The spatial dimension could be used to analyze the changing pattern of locations and venues where commercial hospitality is provided. The physical and/or behavioral dimensions could be used to develop product/brand positioning maps, and the temporal dimension to reflect changing patterns of time use, social trends and priorities, and their relationship to changing forms of commercial hospitality provision (Brotherton, 2003).

The history of hospitality, according to O'Gorman, goes back to 500 B.C. to 500 A.D. generally referred to as the ancient world or classical world that emerged in Greek and Roman Civilizations. The key influences affecting the attitudes towards hospitality in the societies considered are: religious practices and beliefs, the advancement of trade and commerce, transactional expectations, social status and the household, a system of communication, and the fear of strangers. The evaluation of outcomes leads to the identification of five dimensions of hospitality. The dimensions are honorable traditions, fundamental to human existence, stratified, diversified and central to human endeavors (O'Gorman, 2007, pp. 27-28).

Honorable tradition: The common features of the honorable tradition dimension of hospitality are:

- The concepts of guest, stranger, and host are closely related;

- Hospitality is seen as essentially organic, revealing much about the cultural values and beliefs of the societies;

- Reciprocity of hospitality is an established principle;

- Providing hospitality is paying homage to the gods- a worthy and honorable thing to do - and failure is condemned in both the human and spiritual worlds (O'Gorman, 2007, p. 8).

Hospitality is initially concerned with the protection of others in order to be protected from others. Additionally within the ancient and classical words, often reinforced by religious teaching and practice, hospitality is considered as an inherently good thing to provide, without any immediate expectation of an earthly reward.

Fundamental to human existence: The common features of the dimension of the fundamentalism of hospitality to human existence are: 
- Hospitality includes food, drink and accommodation and is also concerned with the approach to be adapted, for example welcoming, respectful and genuine;

- Hospitality is offered and the extent or limitation of it is based on the needs and the purpose of the guests/ strangers;

- Alliances are initially developed through hospitality between friends, households and states, and are strengthened through continuing mutual hospitality;

- Hospitality once granted between individuals, households, and states is also granted to descendants and through extended friendships (O'Gorman, 2007, p. 28).

Hospitality is a primary feature in the development of the societies that have been considered. It is an essential part of human existence, especially as it deals with basic human needs (food, drink, shelter and security). It is also clear that the concept of the hospitality being based on meeting the needs that the guests have at the time, rather than the type of people that they are, is already established.

Stratified: The common features of the stratification dimension of hospitality are:

- Development in the societies lead to the formal stratification of hospitality: the codification of hospitality being based on whether it was private, civic or business, and on the needs and purpose of the guest/stranger, and their nature or status;

- Reciprocity of hospitality becomes legally defined;

- Civil and business hospitality develops from private hospitality but retains the key foundations- treat other as if in their own home;

- Hospitality management, in the civic and business sense, is established as being centered on persons responsible for formal hospitality, and also for protection of guest/stranger and ensuring their proper conduct (O'Gorman, 2007, p. 29).

Hospitality has never been homogeneous. Since the earliest time, hospitality provision is increasingly codified. As the societies become more sophisticated, the codification of hospitality provides reference points for how to treat a range of guests/ strangers, according to a variety of criteria. Typologies of hospitality also become apparent: private, civil and business/commercial.

Diversified: The common features of the diversification dimension of hospitality are:

- Places of hospitality were initially differentiated primarily by the existence, or not, of overnight accommodation; 
- Individual places of hospitality either offer associated services, or are located near other places of hospitality;

- Originally places of hospitality were for the lower classes, who did not have established networks of hospitality enjoyed by the higher classes;

- Increasing travelling among the higher classes created demands for superior levels of places of hospitality (O'Gorman, 2007, p. 29).

The needs of the host and the guest have always varied; hospitality therefore always had to be able to respond to a broad range of needs.

Central to human endeavor: The common features of the dimension of the centrality of hospitality to human endeavor are:

- Hospitality is a vital and integral part of the societies;

- Shared hospitality is a principle feature in the development and continuation of friendships and alliances between persons, between communities, and between nations;

- Hospitality is the focus for the celebrations of significant private, civic and business events, and achievements throughout life;

- Hospitality is also foreseen as a principal feature of the end of time (O'Gorman, 2007:30).

Since the beginning of human history, hospitality is the mechanism that has been central to the development of the societies, at both the individual and collective levels.

\section{Hospitality as Social Control}

Brotherton and Wood (2008) have identified two dominant themes: hospitality as a means of social control, and hospitality as a form of social and economic exchange. Though the distinctiveness of the two themes is debatable, for example, social exchange might be considered as a form of social control (Burgess, 1982; \& Lugosi, 2009). However, the classification has become an important tool of social analysis as has been viewed by Lynch et al. (2011).

Brotherton and Wood (2008) have emphasized the idea of hospitality being a means of controlling the 'other' or 'stranger' which highlights how hospitality acts as a powerful mediating social control mechanism. Historical analyses of hospitality have represented 'stranger' as a potential of danger, civilized through the process of providing hospitality (Selwyn, 2000). To elaborate this, Selwyn (2000) has added that hospitality converts: strangers into families, enemies into friends, friends into better friends, outsiders into insiders, non-kin into kin. Hospitality literature thus also includes antonyms in this regard stranger/friend, inclusion/exclusion, welcome/ non-welcome, hospitality/inhospitality, conditional/unconditional, duty/pleasure, 
morality/transgression, religiosity/bacchanalian, order/disorder and high/low (Bell, 2007a, 2007b; Derrida, 1998, 200b; Selwyn, 2000; Sheringham \& Daruwalla, 2007).

Telfer (2000) has explained that this management of strangers, involving two key participants: the host and the guest, locates the act of hospitality within sociocultural discourses. This, in turn, also contributes to the way individuals manage difference (Cresswell, 1996; Lugosi, 2009). Amidst the ongoing debate regarding the evolution of hospitality focusing upon the influence of commercial hospitality and the contemporary nature of hospitality, attention has been drawn to the different domains of hospitality-social, private and commercial (Lashley, 2000; Lynch, McIntosh \& Tucker, 2009).

Valene L. Smith's (1977) influential collection Hosts and Guests: The Anthropology of Tourism has established hospitality and the related concepts of hosts and guests as a foundational structure to understand the social interactions between tourists and locals in both commercial and non-commercial settings which shifted the focus of tourism studies from tourists to the broader relational aspects of tourism. However, with respect to the increasing commercialized nature of hospitality, Aramberri (2001) has proposed local people and tourists to be described more accurately as 'service providers' and 'customers'.

Hospitality has often been used to control strangers and outsiders, and its giving and receiving offers a way to negotiate potentially harmful relationships between individual and groups (Candea \& da Col, 2012; cited in Lugosi, 2014). The offer of hospitality positions the provider as host and the receiver as guest, each with obligations towards the other (Lashley \& Morrison, 2000). Hosts have duties to ensure the well-being of their guests, while guests have obligations to respect the rules of the host and to reciprocate; both are subjugated to the hospitality transaction and to the creation of a hospitality's space (Derrida \& Dufourmantelle 2000; cited in Lugosi, 2014). The offering and acceptance of hospitality specifies and distinctions between host and guest. In short, hospitality was and continues to be used to create social ties and extend the scope and depth of existing ties through the articulation of host- guest relations (Selwyn, 2000).

The writings of Emmanuel Kant (born in 1724-died in 1804), the humanist; Jacques Derrida (born in 1930-died in 2004), the deconstructionist; and Emmanuelis Levinas (born in 1906-died in 1995), the philosopher (Lynch et al., 2011; Gibson, 2003, 2006, 2007; O’Dell, 2007; Friese, 2004; Zlomislic, 2004; Cresswell, 2007; Laachir, 2007; Germann Molz, 2007) have recently inspired much philosophical deliberation on the ethics and politics of hospitality. In these philosophical accounts writers have used hospitality to reflect critically a boarder questions about citizenship, human rights and the ethical treatment strangers. The philosophical and ethical implications 
of hospitality and in particular Derrida's challenging concept of 'absolute hospitality' may shed light on social relations and encounters between strangers in various contexts

Related to the hospitality/stranger theme is the idea of difference management which links hospitality with social issues concerning inclusion and exclusion (Foster, \& Hagan, 2007), welcome and non-welcome (Naas, 2003), tolerance and conflict (Zlomislic, 2004). Kant (1957) also has emphasized the idea of 'universal hospitality' being necessary to enable peace and world citizenship. However, while Kant conceives hospitality to be conditional with guests conforming to acceptable behaviors, Derrida (2001; cited in Lynch et al., 2011) contrasts it with the idea of unconditional hospitality. This has led to discussions regarding hospitality as an ethic as well as the way in which hospitality governs social relations. Jelloun (1999; cited in Lynch et al., 2011) has thus concluded that hospitality moves from difference management to an acceptance of strangeness and difference. This has further led to discussions upon hospitality and racism, hospitality and treatment of asylum seekers, hospitality and deportation, hospitality and the Internet, and hospitality and the homeless. Thus, the idea of 'how we might live with difference' relates to the transformation of human prejudice and the enactment of liberal values (Valene, 2008) by creating a hospitable city through cosmopolitan hospitality (Yeoh, 2004; Dines \& Cattell, 2006; cited in Lynch et al., 2011). This, as such, focuses upon the theme of hospitality as an ethic.

The intersection between hospitality and mobility explains the questions of hospitality and social control. Hospitality is premised on the mobility of the visitor, the stranger, the exchange student, the tourist or the asylum seeker. However, hospitality also entails immobility as it connotes slowing down, resting and stopping for a while (Germann Molz \& Gibson, 2007). Thus hospitality involves both movement and stillness, as well as the dialects of social control and resistance as hospitality may entail enforced immobility as well as voluntary mobility and stillness.

Bell (2007b; in Lynch et al., 2011) has focused upon the contribution of commercial hospitality to the cityscape, has pointed to the social significance of mundane moments of hospitality in daily life determining the ethics of social relations. Bell (2007a) has drawn attention to the mediating role of built environment, in the affordance of daily hospitality. Thus, apart from host-guest metaphor, hospitality also has examined human and non-human relationships, including divine-human relationships, terra-human or human-animal relationships which also open up new possibilities for thinking about the relationship between humans and machines.

Hence, hospitality accentuates social ties. Strangers are converted into friends by the process of providing hospitality. This eventually contributes to the way individuals manage difference. Focus, today, has shifted from tourists to the broader relational 
aspects of tourism. The theme of hospitality goes further as an ethic. This is because hospitality moves from difference management to an acceptance of strangeness and difference. Its ideas appear relevant in various social issues as well concerning inclusion and exclusion, tolerance and conflict, racism, treatment of asylum seekers, homeless, etc. through the transformation of human prejudice and enactment of liberal values. Therefore, hospitality entails social significance where people could not just manage differences but even accept them.

\section{Hospitality as Social and Economic Exchange}

Various definitions and descriptions of hospitality have shown the diffusion of the ideas of exchange and reciprocity into hospitality. Economic and social exchange has been reflected in the idea of exchange in relation to 'mainstream rational economic theory' (Shilling \& Mellor, 2001; Scott, 1995), recent 'rational choice' and gift exchange (Mauss, 2002; cited in Brotherton, \& Wood, 2008). The ethical economy, as described by Lazzarato (1997), is concerned with 'an ethical surplus'. The ethical economy is motivated by an accumulation of social recognition led by sharing and generosity to acquire peer respect (Arvidsson, Bauwens, \& Peitersen, 2008; cited in Lynch et al., 2011). There have, however, been discussions upon hospitality and hospitableness. There are many dualisms in hospitality: social/economic, gift economy/capitalist economy, nostalgia/real. While hospitality is hoped to embody the real: real people, real values (Featherstone, 1987; Kroker 1985; cited in Lynch et al., 2011), hospitality as economic exchange locates hospitality as part of capitalist economy with a concern for profit realization.

Reciprocity in hospitality has been conceived by Sahlins (1965; cited in Brotherton \& Wood, 2008) as unidirectional, balanced and even negative. For Jelloun (1999), hospitality does not always imply reciprocity and Bolton (2009) has described it as creating 'a distorted relationship'. Thus paradoxes have been highlighted in Lynch (2007) referring to a commercial and highly regulated setting made to entice the guest to consume in free will but which may instead create a loss of free will. Sheringham and Daruwalla (2007) have also drawn out that while 'the other' is symbolically elevated, s/he is also subject to domination by the host and by the rules of being a guest. Lashley et al. (2007) as such prefer the term 'transaction' which has been referred to as 'altered state', 'a liminal space' and the 'time out of the everyday' which hospitality brings. This transaction also focuses upon the interchangeability of the host-guest roles during the hospitality interaction. Lugosi (2008, \& 2009) has drawn attention to the guest-guest relation in hospitality with guests taking on roles of hosts in relation to other guests.

Many studies have challenged the host-guest relationship in the context of commercial hospitality. Aramberri (2001) has suggested 'service provider-consumer' 
relationship to give greater emphasis to the economic rather than social side of the exchange. Hospitality, as such, can be recognized through a variety of motives and ethical positions such as commercial hospitality, ulterior-motives hospitality, reciprocal hospitality and genuine altruistic hospitality.

Hospitality organizations have served to surface broader social themes. They have been used to highlight labor issues such as poor working conditions (Orwell, 1993; Ehrenreich, 2001; Wood, 1997; cited in Lynch et al., 2011), work-group behavior including conflicts (Whyte, 1948), and the significance of emotional labor (Hochschild, 1983). According to Hoschschild (1983, p.7), He uses the term emotional labor to mean the management of feeling to create a publicly observable facial and bodily display; emotional labor is sold for a wage and therefor has exchange value. Emotional labor is implicit or explicit requirement within a job specification to control personal emotional responses and manage or manipulate the emotional well-being of customers or client as a significant aspect of many jobs in the industry (Hochschild, 1983).

Hospitality and the related roles of 'host' and 'guest', thus serve as powerful metaphors to understand the dynamics of control and exchange that shape economic and social life in an increasingly mobile world.

Apart from just providing and receiving service, hospitality is also concerned with economic exchange for profit realization. Hospitality thus, becomes a 'transaction', an interaction, which brings the 'time out of the everyday'. Hospitality is associated not just with pleasing others but also with the reciprocal motives of seeking benefit focusing upon mutual recognition. Besides the 'host-guest' approach, the 'service provider-consumer' relationship also gives emphasis to the economic side of the exchange. Hospitality has even surfaced broader social themes like poor working conditions of labors, work-group behavior including conflicts and the significance of emotional labor. Hence, hospitality serves to understand the social and economic dynamics of control and exchange.

\section{The Hospitality Business}

While reviewing the work of Lashley and Morrison's (2000) book and Brotherton's (1999) article, Slattery (2002) comments the three-domain approach explicitly excludes essential features of the industry so that what is left is a denuded and sterile conception of commercial hospitality and hospitality management that is portrayed as a poor relation to the hospitality available in the social and private domains. There are three levels of context, which are necessary for understanding the business and when incorporated, render the three-domain approach redundant for understanding the industry and therefore redundant as a basis for teaching and research in hospitality management (Slattery, 2002:23).Nailon (1981; Hepple et al.,1990:307) stress that the hospitality industry is a business. The importance of the financial component in many 
types of non-domestic hospitality, for example, hotels, motels, restaurants and wine bars is clear. This is how Slattery made an attempt to establish his own concept on hospitality which cannot be ignored in this study. Accordingly, Slattery proposed three different contexts: the industry context, the corporate context and the venue context.

The industry context: The hospitality industry is comprised of commercial organizations that specialize in providing accommodation and/or, food, and/or drink, through a voluntary human exchange, which is contemporaneous in nature, and undertaken to enhance the mutual well-being of the parties concerned (Brotherton, \& Wood, 2000). Based on this review, it begs the question - Are there any areas of agreement that would support the nation that hospitality literature, there seems to be some level of agreement that hospitality industries are those that are providers of food, beverage, accommodation, entertainment, leisure, attraction, or some combination of those. Second, many of the simplistic dimensions, such as tangibility, degree of labor intensity, service technology, and so on do little to differentiate hospitalityrelated industries from other service industries (Ottenbacher et.al., 2009).

Based on this , it begs the question - Are there any areas of agreement that would support the nation that hospitality literature, there seems to be some level of agreement that hospitality industries are those that are providers of food, beverage, accommodation, entertainment, leisure, attraction, or some combination of those. Second, many of the simplistic dimensions, such as tangibility, degree of labor intensity, service technology, and so on do little to differentiate hospitality-related industries from other service industries (Ottenbacher et al., 2009).

This industry is represented in every country in the world and is diverse and complex. It encompasses a range of free-standing hospitality business and is also a component of a wide range of venues whose primary function is not hospitality (Slattery, 2002).

Slattery further writes, as hospitality venues develop in size and complexity they include common place activities that do not fit with the three- domainers' conception of hospitality. For example, most mid-market, up-market and luxury hotels have facilities to meet demand for conferences and health clubs. Similarly, cruise ships, theme parks, motorway service areas and multi-leisure centers have integral components that fall outside the scope of the three- domainers' definition. A vivid example is from Las Vegas where there are 29 venues, each with more than 100 rooms (Slattery, 2002).

Hospitality companies also have progressively undertaken the management of leisure venues that include hospitality. The range of natural activities managed by hospitality companies extends beyond the minimal of renting rooms and selling meals and drinks as they seek to identify and supply facilities to meet the progressive 
growth in diversity of customer demand. Hospitality is an integral part of leisure venues and it devalues them to strip out the hospitality. For instance, in the UK bingo market the game itself is regulated to be virtually margin free (Slattery, 2002).

The corporate context: As economies develop, so the hospitality industry consolidates and chains of hospitality businesses replace unaffiliated venues as the key operators in the industry. In the UK, for example, between 1985 and 2000 quoted and unquoted hotel chains grew room stock by 59 per cent, adding a net average of 5300 rooms per year. They now account for 56 per cent of UK hotel rooms and the growth is continuing (Slattery, \& Roper, 1986; Hotel and Catering Research Centre, 2001; in Slattery, 2002). Consolidation is occurring throughout the range of hospitality businesses and is the most significant long-term development in the structure of the industry (Slattery, 2002).

When the unit of analysis is the hospitality chain, then the corporate management of the business becomes central and an array of priorities emerge such as the performance of the chain and the conception and management of hospitality brands, which have no part to play in the social and private domains. Two other examples illustrate the divergence. First, corporate executives manage hospitality portfolios and this involves chain supply management. There are eight chain supply variables with which they juggle: market level profile, configuration of facilities profile, size of venue profile, affiliation profile, chain length profile, chain size profile, country profile and city profile (Slattery, 2002).

According to Slattery, there is no reference in the book to the corporate context of the hospitality business and there is no evidence that the three-domainers recognize the centrality of the corporate context to the understanding of the hospitality industry. The corporate context has no parallel in the social or private domains, and the more attention that is given to its realities, the less relevant is the three-domain approach (Slattery, 2002).

The venue context: Within the hospitality industry all hospitality events occur in specific venues while the diversity of supply profile of the venues creates the condition for a diversity of hospitality experiences. There are two features that constrain the three-domainers' understanding of hospitality venues; the first is there insistence that hospitality is about providing accommodation, food and drink (Slattery, 2002).

\section{Spaces of Hospitality}

This is another important aspect of hospitality studies developed by Bell (2009). In applying a spatial analysis and mapping sites of hospitality through the lens of the 'holy trinity', Bell $(2009$, p. 24) has illustrated some ways of understanding how the idea (and ideal) of hospitality is reshaping places. The study has been focused on cities but not uniquely urban. The main characteristics of city are to have various 
forms of inter-urban competitiveness in the context of post- industrialization. Bell has explored urban "foodscapes", "drinkscapes", and "restscapes" which are considered as "hospitality after" that have been reshaped the urban landscape just as 'entrepreneurial governance' has reshaped how cities behave, indeed what it means to be a city.

Bell (2009) in this regard has used the term "holy trinity", first used by Brotherton (1999) which refers to food, drink and accommodation in business and managerial terms. While elaborating this concept Bell writes, 'Here we conjure the specter of "calculative hosting" the cynical performance of hospitality laid on for the safe purpose of getting paid (or getting rich)'. Here too we see "calculative guesting" where by guests expect certain level of service (and servility) simply because they are buying it and the whole beauty of pure, open, unquestioning hospitality relationship is sullied and spoiled by being bought and sold. With these theoretical model of understanding hospitality in the field of business and management, Bell is in favor "critical" hospitality studies of labor relations (Collins, 2008; \& Tufts, 2006; cited in Bell, 2009).

Foodscapes: The highest valued guests, members of the so-called transnational business class, to a large extent function as taste-makers able to define what counts as legitimate good taste, and to fashion markers of good taste into lifestyles (Featherstone, 1991; cited in Bell, 2009). The urban landscape is reshaped to provide high-end consumption experiences for these taste-makers, including foodscapes.

Of course, for most traveler-diners, foodscapes are commercial hospitality venuescafes, restaurants, delis, trattoria. While the fetish of home-cooked food means that gastronomic delights are available from "commercial home" settings, a more common way in which "home" is parlayed in foodscapes is through the deployment of signs of geographical distinctiveness and localness (Bell, 2009). Cities with iconic foodstuffs or foodscapes can center their tourist economy on this segment of the hospitality offer, and build a brand from it. At the same time, of course, foodscapes have been globalized (a better word might be "glocalized").

This study further elaborates the important final point about performance of gastronomic hospitality is their staging: restaurant architecture and interior design serves to make some eating places tourists destinations, sometimes regardless of the quality of the food on offer (Frank, 2005).

Drinkscapes: The discussion of drinking places, hospitality and tourism will be limited to the consumption of alcoholic drinks in urban drinkscapes. This is not to deny that other kinds of drinking places, from coffee houses to tea rooms, juice bars to watering holes, are equally important components of the overall experience of drinking in the city - and, indeed, the country. The previous research on 
"alcotourism" shows that people travel to drink, drink while traveling, or even drink to travel (Bell, 2008). The drinkscape is part of the broader "urban nightscape", the so-called "nighttime economy" (Bianchini, 1995; cited in Bell, 2009) that Chatterton and Hollands (2003) has described as contributing a new "feel" to cities, a new sense of what urban experience might mean, and a new set pleasures and problems for city dwellers and visitors. The desire to promote a new "urban nightscape" was also part of a policy agenda to repopulate city centers, in order to address decades of movement out towards the suburbs.

Studies of "alcotourism" reveal more than the vital urban social lives that Montgomery highlights; they reveal a complicated set of practices and imagining, whereby "local" drinking cultures are selectively appropriated, selectively transformed, and selectively ignored by tourists while at the same time tourist' drinking tastes and habits remake "local" alco-cultures (Moore, 1995; cited in Bell, 2009). For some travelers, drink is a taste of home-away-from-home (West, 2006; cited in Bell, 2009), while for others, drinking "local" drinks is a way of experiencing the exotic.

Drink undoubtedly has a special place in the "holy trinity" of hospitality, for its ambivalent ability to oil the wheels of conviviality yet also to lead to antisocial and inhospitable behavior. Concerns over "binge drinking" in city centers have been framed in terms of a loss of the hospitality of "traditional" drinking cultures and places, and the ushering in of a new "inhospitable" alcoculture creating, in the words of Bianchini (2006; cited in Bell, 2009:27) "alcoholic agoras."

In the new nighttime economy of city centers this "welcome" is extended not only by bar staff but also by door staff, tasked with ensuring certain modes of hospitality between guests (Hobbs et al., 2003; cited in Bell, 2009:28). The activities of the nighttime economy bring a different rhythm of hosting and guesting to cities, as drinkers are attracted in the city center, performing certain modes of guestness including those that clash with the lifestyles of unwitting hosts such as city-center residents (Roberts, \& Turner, 2005; in Bell, 2009). Drinking alcohol therefore has a strange location in ways of knowing and thinking about hospitality, and in the ways of practicing it.

Restscapes: As Walton (2000) has shown in his short history of the hospitality trades, foodscapes, drinkspaces, and restscapes share a common heritage in terms of providing hospitality for travelers, and perhaps no institution better embodies the commercial provision of hospitality - usually offering the "holy trinity" under one roof - than the hotel. Moreover, hotels are stages for numerous other enactments of hospitality between host and guest and between guest and guest. As Pritchard and Morgan (2006) have noted the hotel as a "cultural product" has been somewhat neglected in the emerging "critical" hospitality studies. As they add, hotels are 
emblematic of the key issues at the heart of hospitality as a concept, leading them to call upon scholars "to explore the spatiality of the hotel in order to analyze how interior and exterior hotel spaces are made through social relations and how social relations are in turn shaped by those self same spaces" (Pritchard \& Morgan, 2006:770). Iconic in the architecture of the hotel in this regard is the lobby, where outside and inside meet, and the hotel bar, where particular modes of drinking and socializing are mobilized.

From themed hotels to boutique hotels, capsule hotels, business hotels, and apartment hotels, the differentiation of product in the hotel sector is matched by differentiation in design and in the hospitality offer. In a paper solely focused on airport hotels serving business clients, McNeill (2008a; cited in Bell, 2009:29) traces how this particular niche has developed to meet the need of the business traveler, providing a seamless business space where even the guest room is part of the "exoskeleton" of business-class connectivity. As well as hotel types serving distinct niche markets, distinctive local and national restscapes have developed, even while glocalized hotel brands have spread to new locations (McNeill, 2008b; cited in Bell, 2009). In Japan, for example, novel forms such as the capsule hotel and the love hotel have appeared. The former offers minimal sleeping accommodation with none of the added extras familiar from standard hotel rooms and suites - "rooms" can be simply "pods" in which to sleep - while love hotels offer discretion via automation and hourly room rates for intimate liaisons (Foster, 2007; in Bell, 2009).

Indeed, iconic hotels have long been embedded in the place myths of particular cities, even as those myths change with time (Wharton, 2007; cited in Bell, 2009). So the exterior architecture also has symbolic importance in communicating certain values, hence the increasing call for "starchitects" to design restscapes (McNeill, 2008b; cited in Bell, 2009).

\section{Host - Guest Relationship}

The philosopher Max Beerbohm divided society into two classes - hosts and guests - based on the instinct to either offer hospitality or to accept it (O'Connor, 2005; cited in Mill, 2008, p. 103). It can be argued that there are two schools of thought. One sees the host-guest relationship entirely based on commercial transaction between them (Aramberri, 2001; Slattery, 2002). Another sees hospitality as a social phenomenon (Smith,1977/1989; Lashley \& Morrison, 2000; Lashley et al., 2007). For social scientists, it is clear that hospitality is not just about an encounter with a guest (Rosello, 2001) and providing a service. A more generic approach to hospitality sees host -guest relationships as a social phenomenon (Causevic \& Lynch, 2009).

Both Simmel (1950) and Schutz (1944) have discussed the stranger as someone who is outside of an "in-group" in many respects the category of the stranger is 
necessary to the group' s understanding of itself in that it allows another against which the in-group can be defined. The position of the stranger is also one of ambiguity as the etymology of the world linking it to both guest and enemy demonstrates (Zarkia, 1996). Further, as Schutz (1944) has noted, the lack of knowledge of the stranger about the assumptions held by the in-group engenders a feeling of insecurity and disorientation (Andrews, 2000). For Pickering (2001; cited in Brotherton \& Wood, 2008) strangers occupy an inherently ambivalent position in society because they are 'neither socially peripheral nor symbolically central but somewhere particularly between'.

According to the sociological and anthropological principles, the relationship between host and guest is grounded in the nature of social life it would be difficult to imagine how society would be possible without hospitality (Selwyn, 2013). Majority of the scholars agree that hospitality brings together hosts and guests for occasions in which social relationships are symbolized by the reciprocal giving of goods, services, well-being, honor and status. It is routinely offered an occasions when strangers are welcomed to mark the making of alliances between new friends-in places as diverse as the public spaces of the city and or the more private (Selwyn, 2013).

Aramberri (2001) has subsequently suggested that the host should 'get lost; arguing that the commercial interactions now common in tourism contravene 'the world covenant' of hospitality. On the contrary, he preferred to say that local people and tourists are 'service providers' and 'customers' than as host and guest. He argues that the modern experience no longer content these elements of exchange and obligation. This approach reframes the nature of the relationship between the host and guest and has given a greater emphasis to the economic rather than social side of the exchange. In this regard, Slattery (2002) also has rejected the relationship of host- guest descriptors, used by Lynch and Whannell (2000) in reference to commercial home accommodation as coming from the private domain. Commercial home accommodation is described as quasi hotels. But, Lynch (2005) is not in a position to accept the criticisms of Aramberri (2001) and Slattery (2002) because there has been found both private and commercial domains reflected in myriad host and guest behaviors.... He believes that hotels, restaurants, bars and the other hospitality venues are businesses where the critical relationship is sellers and buyers. The buyers are not guests they are customers. The relationship is not philanthropic, it is economic.

According to Nettekoven (1979; cited in Reisinger, 2009), the host can be local residents, indigenous residents, investors, developers and those who provide a service to tourists (e.g. hoteliers, front office employees, waiters, shop assistants, custom officials, tour guides, tour managers, and taxi and bus drivers). The service providers are often called "professional hosts". In the context of writing tourism and hospitality, 
Bell (2009) has also mentioned about the status of the host and guest. As he writes, the host is static, fixed, rooted, while the guest is footloose, on the moves, rootless. This asymmetry defines the very 'host-ness' of the host and the 'guest-ness' of the guest. The host is at home, either literally in his house or more broadly in his homeland; the guest is an incomer, a visitor, a stranger (Bell, 2007). Sheller and Urry (2004:8; cited in Bell, 2007) write, in the context of tourism: 'many "hosts" are increasingly also from elsewhere, are also on the move, passing through, guests enacting host-ness. Hospitality - as a relationship marked by poles of host-ness and guest-ness, and by the obligations and rewards that this bipolarity brings - is thus itself destabilized as we enter an increasingly mobile age, a society of mobility. The professional hosts are hoteliers, front office host, waiters, shop owners, custom officials, tour guides, tour managers and taxi and bus drivers. The non-professional host are local people.

Rosello (2001), as cited by Germann Molz \& Gibson (2007) has stated, "Hospitality is not just a metaphor for reflecting on encounters with the strangers, but, according to Urry (1990), serves more broadly as a central concept for the emergent paradigm of 'mobility'. Hospitality is a structure that regulates, negotiates, and celebrates the social relations between inside and outside, home and away, private and public, self and others (p. 3). Implicit in most definitions of hospitality are the movements of tourists and visitors (those mobile others who come and go) as well as the movements of migrants, asylum seekers, and refugees (those mobile others who come and stay).

The binary "host-guest," the cornerstone social relationship of any tourist system, has also been contested (Sherlock, 2001). "Hosts" are frequently themselves "guests" in little developed destinations, wherein outsiders often engage in tourist business (e.g. country, often also assume the role of host through casual employment in tourist enterprises (Janta et al., 2011; cited in Cohen \& Cohen, 2012). To host or to be hosted are both forms of travelling- in- dwelling and dwelling- in- travelling where the mobility of guests, travelers and foreigners intersects with host and homes (Germann Molz \& Gibson, 2007).

\section{Hospitality Management and Hospitality Studies}

These two broader areas are very important in the study of hospitality first and tourism second. For many decades, hospitality studies has been pre-dominated by hospitality management .Therefore, it is very important to know what is hospitality management? Precisely nothing. There is hospitality and there is management. Both are social, economic, and political activities. Both are the products of human action. Neither can be granted any epistemologically privileged status. Both, however, can be more or less defined, or, more precisely, circumscribed. It is Nailon (1982) who for the first time theorized what hospitality management is. According to him, "Hospitality management can be seen as the active co-ordination and balancing of the inter- 
relationship of the four systems represented by the external environment, the human resources, the technical infrastructure and the management information system. Its purpose is to provide physiological and psychological comfort and security as a business activity at a defined standard of service through provision of facilitating goods" (Nailon, 1982).

King (1995, p. 220) has pointed out, 'Effective management of hospitality in any type of organization must begin with a clearly understood definition of what hospitality is.' If it is accepted that hospitality may arise in both private/domestic and public/commercial contexts, it is also logical to suggest that the management of hospitality provision occurs in both contexts (Brotherton, \& Wood, 2000).

The definition of hospitality management existing in the literature tends to be typified by a primary concern with emphasizing a particular product/service focus. However, as King (1995) has accurately pointed out, "Effective management of hospitality in any type of organization must begin with a clearly understood definition of what hospitality is" (p. 220). If it is accepted that hospitality may arise in both private/domestic and public/commercial contexts, it is also logical to suggest that management of hospitality provision will equally occur in both contexts.

In essence, the concept of hospitality management embraces two key assumptions, namely:

- hospitality management is about the management of (essentially but note exclusively) commercial organizations in the business of providing the three key related services of food, drink and accommodation; and

- hospitality management principally entails the application of management concepts and techniques to the provision of these goods and services (Brotherton \& Wood, 2000:145).

Whether management is primarily regarded as an art, a science, a function or a process, Fayol's (1949; cited in Brotherton, 1999, p. 170) view that is concerned with coordinating, communicating, controlling, planning and commanding is generally accepted. All these fundamental aspects of management are to be found in the management of hospitality exchanges within both domestic and commercial contexts, regardless of whether such exchanges take place for social or economic motives.

The key issue there is not necessarily the context of, and/or motive for, the hospitality exchange but the nature of its management. It is the distinction between managing hospitality and hospitality management. As hospitality occurs in both private/domestic and public/commercial environments, issues concerning the management of hospitality equally arise in both type of environment. The distinction 
between managing hospitality and hospitality management, given the generally accepted use of the later term, lies in the concept of a profession and the existence of a hospitality management professionals. Many employees in the hospitality industry would fall into professional category. For example, many employees engaged as professional food and beverage production and / or service staff are an integral part of hospitality provision but they would not be regarded as hospitality mangers. They would, however, be regarded as hospitality professionals, or professional hospitality staff (Brotherton, 1999, p.171).

This view implies that there will be individuals involved in managing some aspects of public/commercial hospitality exchanges, but who should not necessarily be regarded as hospitality managers. They are also known as hoteliers. In this regard, Brotherton (2013, p. 59) has proposed to basic perspectives on hospitality and management. Accordingly he writes, people initiatively understand what 'hospitality' and management are because they have experienced both as recipients and practitioners. Two basic perspectives have been used to define hospitality's nature and meaning. One may be described as the behavioral 'perspective' the second may be described as the 'industry' or 'provider' view.

Important and desirable though such attributes may be, only through the development of a theoretical framework for hospitality management can the competent become effective, while those who are truly able can achieve excellence (Nailon, 1982). The quality of hospitality services is a major underpinning of corporate success - as gauged by profits. For example, a hotel can be depicted as a three-legged stool with the seat representing profits. The three legs represent the major factors to support these profits - the quality of hospitality service, management, and the market. The only assurance for profitability is strength and balance in all three legs. A hotel cannot expect to succeed with inferior services, or even with services for which there is no market. Similarly, a hotel with superior services having a strong market potential cannot succeed if it lacks the marketing, technical or production knowhow that can deliver these services or attract sufficient guests to maintain levels of occupancy (Haywood, 1983, p. 166).

Lashley (2004,p.15; cited in Lashley et al., 2007) has summarized that the debate between an emphasis on management versus that of studies, as follows: 'the study of hospitality allows for a general broad spectrum of enquiry, and the study for allows studies that support the management of hospitality'. This statement explicitly acknowledges that the intellectual growth and progression of hospitality as an academic field of study is best served through the critical analysis of the concept of hospitality as broadly conceived.

It is apparent that hospitality as a higher education academic subject is evolving 
and maturing from its beginnings as confined to management and industry. One reflection of hospitality's advancement towards an academic maturity is in the emergence of alternative schools of thought (Littlejohn, 1990; Jones, 2004). Within the contemporary hospitality academic community those that dominate are termed as 'studies' and 'management'. The former is derived from the social sciences applied to hospitality in its many guises, and not only within an industrial context as suggested by Jones (2004). It facilitates analysis of hospitality as business and as cultural phenomena; not necessarily unrelated; a view supported by Wood (1999), Lashley (2000) and Airey and Tribe (2000). The latter is concerned with hospitality as industry, commercial endeavor, and business and management therein (Morrison, \& Lynch, 2007). It has become apparent that the study of hospitality can usefully co-exist with that of hospitality management, as the difference between them is essentially one of emphasis (Jones, 2004). Hospitality studies allow for the intellectual pursuit of the social dimensions, alongside those of an economic nature.

One of the problems with the current state of hospitality studies is that different disciplines and sectors frame hospitality in quite distinct ways. Even a brief review of the literature reveals that scholars and practitioners are approaching hospitality from very different perspectives and with very different objectives. Hospitality is framed quite differently in the social science than it is in the managerial sciences (Lynch et al., 2011). In an effort to capture the essence of the hospitality studies. Morrison and O'Gorman (2006) have made a preliminary attempt to craft a working definition as follows:

It [hospitality] represents the cordial reception, welcome and entertainment of guests or strangers of diverse social backgrounds and cultures charitably, socially or commercially with kind and generous liberality, into one's home space to dine and/or lodge temporarily. Dependent on circumstance and context the degree to which the hospitality offering is conditional or unconditional may vary.

Thus, it is argued that the hospitality studies school of thought has the potential to contribute to: 'the creation of new knowledge that is not merely wed to unitary business, industry and/or management ways of knowing what is hospitality.

Table 3: Examples of key contributions to hospitality subject development

\begin{tabular}{|c|l|}
\hline \multicolumn{1}{|c|}{ Authors } & \multicolumn{1}{c|}{ Contribution } \\
\hline Cassee (1983) & $\begin{array}{l}\text { Emphasis the interrelatedness of the hospitality industry with } \\
\text { the outside world. }\end{array}$ \\
\hline Slattery (1983) & $\begin{array}{l}\text { Advocates the application of existing social science theory to } \\
\text { hospitality management. }\end{array}$ \\
\hline
\end{tabular}




\begin{tabular}{|l|l|}
\hline Wood (1988) & $\begin{array}{l}\text { Argues for sociological approaches to the study of hospitality } \\
\text { management. }\end{array}$ \\
\hline $\begin{array}{l}\text { Littlejohn } \\
(1990)\end{array}$ & $\begin{array}{l}\text { Allows for an approach to hospitality industry research that } \\
\text { draws on the social sciences. }\end{array}$ \\
\hline Jones (1998) & $\begin{array}{l}\text { Recognizes a need for multi-disciplinarily and the difficulty in } \\
\text { achieving it. }\end{array}$ \\
\hline $\begin{array}{l}\text { Airey and Tribe } \\
(2000)\end{array}$ & $\begin{array}{l}\text { Points to the preoccupation with the world of work rather } \\
\text { than the many disciplines or fields of enquiry that help explain } \\
\text { hospitality. }\end{array}$ \\
\hline $\begin{array}{l}\text { Lashley et al. } \\
(2007)\end{array}$ & $\begin{array}{l}\text { Identify a contemporary willingness of the academic } \\
\text { community to extend the conception of the hospitality subject } \\
\text { boundaries, and associate this process as positive for the subject } \\
\text { development and its consequent academic standing. }\end{array}$ \\
\hline
\end{tabular}

Source: Morrison \& O'Gorman, 2008:216

Table 4: Illustrative examples of disciplines engaging in research into the phenomenon of hospitality

\begin{tabular}{|l|l|l|}
\hline Field & Focus & Authors \\
\hline Anthropology & $\begin{array}{l}\text { Observes current practices among the desert } \\
\text { clearly indicating the importance and centrality of } \\
\text { the hospitality practices to their way of life. }\end{array}$ & $\begin{array}{l}\text { De Vaux } \\
(1961)\end{array}$ \\
\hline Archaeology & $\begin{array}{l}\text { Interprets and excavates the use of commercial } \\
\text { hospitality buildings and structures, in order } \\
\text { to understand more about how people lived in } \\
\text { historical locations. }\end{array}$ & $\begin{array}{l}\text { Ellis } \\
\text { (2004a, b) }\end{array}$ \\
\hline Biblical studies & $\begin{array}{l}\text { Explores the origins of hospitality demonstrating } \\
\text { that hospitality is not a simple concept it contains } \\
\text { deeply rooted cultural norms. }\end{array}$ & $\begin{array}{l}\text { Matthews } \\
(1991, \\
1992)\end{array}$ \\
\hline $\begin{array}{l}\text { Uses the theme of hospitality to give significantly } \\
\text { richer understanding of the structure of the } \\
\text { Homeric epics, by demonstrating that successive } \\
\text { oral poets who redacted the Homeric poems, used } \\
\text { to concept of hospitality as recurrent theme. }\end{array}$ & $\begin{array}{l}\text { Reece } \\
(1993)\end{array}$ \\
\hline
\end{tabular}




\begin{tabular}{|l|l|l|}
\hline Deconstruction & $\begin{array}{l}\text { Defines hospitality as inviting and welcoming the } \\
\text { 'stranger': however, this takes place on two levels: } \\
\text { the personal level where the 'stranger' is welcomed } \\
\text { into the home; and at the level of individual } \\
\text { countries. Using the conceptual possibility of } \\
\text { unconditional hospitality to understand and to } \\
\text { inform what is going on today in our world. }\end{array}$ & $\begin{array}{l}\text { Derrida } \\
\text { (1998, }\end{array}$ \\
\hline Gender studies & $\begin{array}{l}\text { Observes that symbols, verbal and non-verbal } \\
\text { communication, and value of sociability and } \\
\text { physical attractiveness contributes to a sexualized } \\
\text { work environment that is likely to encourage and } \\
\text { draw attention to gender-specific behaviors. }\end{array}$ & $\begin{array}{l}\text { Brownell } \\
(2001)\end{array}$ \\
\hline Philosophy & $\begin{array}{l}\text { Pursues the reality and principles underpinning } \\
\text { hospitality as a phenomenon. }\end{array}$ & $\begin{array}{l}\text { Telfer } \\
(1999)\end{array}$ \\
\hline $\begin{array}{l}\text { Post-colonial } \\
\text { theory }\end{array}$ & $\begin{array}{l}\text { Investigates the politics of hospitality exploring } \\
\text { issues including democracy, citizenship, social } \\
\text { exclusion, xenophobia, and racism to reveal the } \\
\text { ethics and politics of hospitality and the status of the } \\
\text { stranger, visitor, migrant, asylum seeker, and refugee. }\end{array}$ & $\begin{array}{l}\text { Ben } \\
\text { Jelloun } \\
(1999)\end{array}$ \\
\hline Sociology & $\begin{array}{l}\text { Explores the role of hospitality in society in } \\
\text { particular in forming communities. }\end{array}$ & $\begin{array}{l}\text { Heal } \\
\text { Constructs and deconstructs the role, meaning, } \\
\text { and symbolism of hospitality in society. }\end{array}$ \\
\hline Social history & $\begin{array}{l}\text { Goffman } \\
(1969)\end{array}$ \\
\hline
\end{tabular}

Source: Morrison \& O’Gorman, 2008:216

Jones (2004) has noted that hospitality research is still lagging behind those fields.

- Hospitality science model: Based on the natural and physical sciences such as chemistry, biological and physics. Studies of this type include research in diet, nutrition, ergonomics, equipment performance and so on.

- Hospitality management school: This largely based on empirical and quantitative studies, often related to studies of hospitality marketing and consumption.

- Hospitality studies: This includes qualitative as well quantitative research.

- Hospitality relationship: This is recent school of thought and separate to, and distinct from, any management or industry association.

- Hospitality system: System thinking accommodates both positivist and normative research. 
- Hospitality pragmatics: This is an inclusive position dealing with the realities of the industry.

\section{Typology of Hospitality}

Hospitality has never been homogeneous. Since the earliest time, hospitality provision is increasingly codified. As the society become more sophisticated, the codification of hospitality provides reference points for new to treat a range of guests/ strangers, according to a variety of criteria. Typology of hospitality also becomes apparent (O'Gorman, 2007). Clearly hospitality provision may exist on a large or small scale, take a number of different forms depending on whether it occurs within private/domestic or public/commercial contexts, and be provided for primarily social or economic motives (Brotherton, 1999: 167-168).

There are many other types of hospitality researched by different scholars in different aspect of hospitality. None of them have comprehensively elaborated the particular types of hospitality in terms of developing hospitality classification. Therefore, the present author made efforts of collecting the particular types of hospitality defined and described by different scholars in different studies of hospitality. They coined the terminologies according to the nature, function, events, relations, religion, ethics, spaces and places, business, academic, ideology, philosophy, behavior, aggression, tradition and changes of culture, norms, values of human society. Whatever types of hospitality have they mentioned all those help to understand hospitality as human phenomenon in better way. In this classification, social hospitality has not been included because this has become the central part of this study because of considering hospitality either as human phenomena or social phenomenon as mentioned.

Before heading towards typology one should go through two components of English that are denotative and connotative meaning of words. Denotative meanings are dictionary meaning of words and connotative are the meanings that comes out when pronounce along with other subtle words, all the types of hospitality which has been discussed have different denotative and connotative meaning. The concerned types of hospitality are as follows: private and public hospitality, hotel hospitality, commercial hospitality, anticommercial hospitality, inhospitable hospitality, hospital hospitality, transgressing hospitality, hybrid hospitality, commensal hospitality, pseudo- hospitality, mundane hospitality, airport hospitality, simulated hospitality, corporate hospitality, asymmetric hospitality, critical hospitality, mobile hospitality, genuine hospitality, official hospitality, academic hospitality, intellectual hospitality, linguistic hospitality, Embodied hospitality, divine hospitality, open hospitality, personal hospitality, intra- tribal hospitality, conditional and unconditional hospitality, universal hospitality, absolute hospitality, civic hospitality. 
Private and public hospitality: In a related but slightly different vein, Burgess (1982) explored the relationship between gift exchanges and hospitable behavior. Burgess (1982) places on the issue of "exchange" in relation to hospitality and the widening of the concept to include private as well as public contexts for the incidence of hospitality. His model essentially contends that hospitality is an exchange transaction comprises three elements; products, employee behavior, and the physical environment.

Though the study of Telfer (2000), Brotherton (2008) and O'Dell (2007) show private (domestic) and public (commercial) hospitality are independent forms, in this studies it has been combinely placed with each other. It is, in short, a morally laden social field of exchange and interaction whose bounds and limits were continuously contested and debated (O'Dell, 2007). For public hospitality more widely however, the problem of the stranger is compounded by the fact the majority of person's who participate in public hospitality are not tourists but permanent members of their communities who use the public hospitality facilitates rooted in those communities.

Hotel hospitality: Ryan (1991; cited in Brotherton, 2007) has noted that the tourists are strangers and bring with them the threat of social, cultural and environmental damage. The tourist is not, however 'simply a stranger, but a temporary stranger... they are guest, but an impersonal guest' (Ryan, 1991; cited in Brotherton, 2007). The consequences of this impersonality for hotel hospitality have been characterized by Wood (1994c; cited in Brotherton, 2007) in terms of the mechanisms that hotels use to control their stranger-guests.

Commercial hospitality: According to King (1995; cited in Thio, 2005), commercial hospitality is 'a specific kind of relationship between a host and a guest in which the host understands what would give pleasure to the guest and enhance his or her comfort and well-being and deliver it generously and flawlessly in face to face interaction. In commercial hospitality, there is a reciprocity based on money exchange. Therefore, the guest is free to use the facilities offered because of the money he/she pays, and the host has an obligation to give the best service that meets his/her needs and expectations.

The term 'commercial' is used very exactly to convey a sense of an activity 'viewed with regard to profit' (Longman, 1992; cited in Lynch \& MacWhannell, 2000). The nature of commercial hospitality as a service operation brings into consideration a further range of characteristics (Fitzgerald et al., 1991) from which it is possible to select four key characteristics that inform any discussion of the management of commercial hospitality. According to Lockwood and Jones (2000), commercial hospitality is not simply domestic hospitality on a large scale. It is different. It is business driven and it shouldn't make any excuses about its underlying business ethic. The challenge facing 
commercial hospitality is to capitalize on the highly developed technologies and systems of operation that are available, enabling employees to provide exactly the food and service that the customer wants and is prepared to pay for it.

Anticommercial hospitality: Anticommercial hospitality is another form of hospitality invented by Di-Domenico (2003; cited in McIntosh, Lynch, \& Sweeney, 2010, p. 8) in the study of Scottish Guest houses. In this study Di-Domenico (2003; as cited in McIntosh, Lynch \& Sweeney, 2010; p. 8) has explained that anticommercial hospitality refers here to behavior of hosts that challenges norms of (larger) commercial hospitality establishment in relation to operation standards, business practices aiming to maximize profitability, commercial accommodation product norms, host-guest social distance. For example, commercial homes in the study contained modest furnishing cleanliness, and facilities and were very low priced, few hosts actively promoted their business, and there was something evidence of compromise of space within the home.

Inhospitable hospitality: This type of hospitality has been mentioned in Ritzer (2007, p. 130). He illustrates that his favorite example of the most inhospitable of placesthe fast food restaurant where 'you are required to do virtually everything yourself'. This scholar has suggested that there are 'McDonaldizing' and globalizing tendencies, particularly in corporate hospitality provision that will create increased 'inhospitable hospitality, in the commercial sector. According to this scholar, the general threat to the hospitality is clear. In terms of the distinctions, the hospitality industry has in the past been based on places, things, people and services but is threatened by a long term trend in the direction of non-places, non-things, non-people and non-services, more generally nothing is virtually the definition of unwelcoming, inhospitable. This scholar is not pessimistic to see the inhospitable hospitality, as it has been concluded that in spite of the problems discussed in this essay, the hospitality industry is in not serious danger - indeed, various trends indicate that it should continue its dramatic expansion of recent decades.

Hospital hospitality: This is another academic product of Hepple et al. (1990) in the study of hospitality typology. The working definition of hospital hospitality suggested that the individual, patient should feel as at home as possible during their hospital stay. The phrase at home is intended to indicate a standard of security, physiological comfort, and psychological comfort which the patient knows and is satisfied with. This phrase does not make allowance for those who have unhappy, unsatisfactory home lives, however, it is suggested that even such patients would be aware of the concept of feeling at home and are likely to take the phrase in the spirit in which it is intended. The inclusion of the phrase as possible in the definition allows for the judgment of the patient to compare their expectations of hospital hospitality with their experience of that hospitality. 
The working definition is intended for us in its specific setting as in other settings for example, in the case of the hospitality of a five star hotel, clients are often seeking a higher standard of comfort than that which they are used to at home. Education within hospital is, however, a worthy aim. And that the hospital is seen to set a good example of healthy behavior seems very reasonable; however the extent of its success, with respect to long-term changes within a community cannot be other than limited.

The study has shown that the concept of hospitality can be applied to hospitals and that those non-medical aspects of hospitals which are important to making patients feel as at home as possible in hospital can be identified and do meet with agreement from a relatively large sample of patients expression their feelings during a hospital stay. The study has also suggested that the hospitality factor groupings suggested in Cassee and Reuland ( 1983), of behavior, product and environment the hospitality factors which relate to behavior are considered to be the most important.

Transgressing hospitality: In the studies based on Sheringham and Daruwalla (2007), transgression hospitality was formed as a means of articulating, demonstrating and manipulating social structures and hierarchies functioning at the interplay between, the likes of, order/disorder, hospitality/hostility, inclusion/exclusion, sacred/profane, religiosity/bacchanalian, reality/fantasy and domestic/commercial (Sheringham \& Daruwalla, 2007, p. 44). Hospitality is a negotiated act between host and guest, and can be described as transgressive in nature in that it infringes thresholds of physical, psychological and symbolic character (Sheringham \& Daruwalla, 2007, p. 33). The guest by accepting the offer of hospitality enters into a negotiated agreement that impacts the host's sense of place. The role of food, alcohol and place as symbols and markers of this transgression from order to disorder are highlighted and the role of religiosity and parallels between carnival and hospitality are also explored. This has served to highlight the transgressive nature inherent in the concept of hospitality, vulnerable as it is to infringement in a multiplicity of ways, and heavy in symbolic connotations.

Hybrid hospitality: According to Foot (1978), based on hospitableness, hybrid hospitality depends on the host's sharing home life with the guests, such hybrid hospitality lacks some value. But in many situations it is perfectly appropriate to entertain guests away from home.

Commensal hospitality: This type of hospitality has been mentioned by March (1987) in the study of hospitality of the Tamang and Sherpa communities of Nepal. While focusing on this type of hospitality, March (1987) describes, in spite of these stylistic differences of hospitality between the Tamangs and Sherpas, commensal hospitality is extremely common and highly valued in both Sherpa and Tamang communities. All transactions begin with a hospitable offering - of cigarettes, tea, milk, food, and other gifts, but above all of "beer" and "whiskey" - that must be accepted and most be reciprocated. 
An offering is effective if or because it creates an ambience of amicable feelings.

Tamang and Sherpa versions of hospitality resemble one another in four essential ways: in an assertion of almost perfectly balanced reciprocity; in the ambivalence surrounding the relative social statuses of participants; in the use of hospitality as a model for religious worship; and finally, in the importance of female symbol of mediation in both human and divine hospitality exchanges.

Pseudo-hospitality: This is another type of hospitality which has been coined by Olesen (1994; in Lugosi, 2009, p. 399) who has examined the notion of hospitality as social transaction when discussing its commercial form, although her work is also concerned with the identity performances of frontline workers. More importantly, pseudo hospitality continues to separate its social forms from its provisions in commercial settings. Such studies of hospitality are thus concerned with the service providers or provision, and with few exceptions (Cuthill, 2007; cited in Lugosi, 2009), other aspects of the experience, including the consumers' perspectives and the contexts of transactions, are rarely considered.

Mundane hospitality: Bell (2007a; cited in Lynch, Germann Molz, McIntosh, Lugosi, \& Lashley, 2011) has illustrated how mundane hospitality occurs through commuting to work on trains, for example, where the host passenger moves their bag from the adjacent seat to make way for another passenger temporarily transformed into the host's (i.e. the bag-removing passengers) guest.

Such mundane forms of hospitality are sometimes offered through extensive provider-consumer interaction (Crang, 1994, in Lugosi, 2009), but in commercial environment food and drink can also be provided with minimal or no interaction between staff and customers or between customers. Therefore, commercial provision may not involve actual hospitableness. In order to justify this Lugosi (2009) has presented the situation of the bar through patronage. Patronage also involved particular identity performances, interaction rituals and mundane hospitality transactions, which reproduced group norms, inside-outside statuses alongside experiences of social proximity and distance.

Beyond acts of welcoming, it is useful to consider how other hospitable transactions are also applied within service settings. Reception spaces and acts of receptions often attempt to incorporate mundane hospitality offerings, in the form of drink and foodstuffs ,but may also extend to access to wireless services, which are referred to hear as gestures of generosity. Gestures of generosity may be used to provide affective relationships between the organization and the consumer (Taher, Leigh, \& French, 1996; cited in Lugosi, 2014). Importantly customers may not be charged for such mundane hospitality, at least not directly, and not all the time.

Airport hospitality: Touristic spaces are sites of consumption and construction, 
with varying and multiphenomenal experiential contexts. Conventional theory of 'non-places' (Auge, 1995; cited in McCabe \& Marson, 2006), such as airport lounges, may in fact be sites of pure anticipatory joy, a chance to look forward to the pleasurable experiences to come and to prepare last-minute shopping enjoy a meal or a drink in a bar. The same place for another traveler may be dull, meaningless and futile; it may be a site of constant use (perhaps for the business traveler or worker) and the experience in this case in tangential, arbitrary, and desensitized. However the temporal aspect is crucial. For example, for the leisure traveler if there is a delay, the site of the airport lounge rapidly changes and becomes a site of anxiety and tension, dispute starts between the tourist and the tour operator or airline operator and the time spent in waiting eats into the precious time of the holiday itself - or the joyous return to the home. The space of the lounge is transformed into a negative, claustrophobic and all consuming environment. The a priori, in situ and a posteriori experience of place is fundamentally significant in the social construction of place and identity (McCabe \& Marson, 2006).

Simulated hospitality: Ritzer (2007) has devised a simulated hospitality which is an unauthentic hospitality where people experience genuinely modified services in modern hospitality industry. This is repeated and sold as an experience to the consumer or tourist. The simulated hospitality is the face of modern service industry and defined as one of the main forms of hospitality. Instead of authentic hospitality, visitors encounter are simulation- fakes- in terms of either people or experience. Thus, natural, authentic attraction of one need to be closed off or modified in order not to be adversely affected, or even destroyed, by the crush of large number of visitors. This means that visitors do not have access to authentic sites but experience simulated sites.

Corporate Hospitality: It is Lugosi (2014), who studied on hospitality and organization in which he has mentioned about a different type of hospitality i.e. corporate hospitality. As he explains that longer-term, repeated transactions of hospitality between external stakeholders and organization can take numerous forms, but a prominent form is corporate hospitality, whether it is entertaining specific clients with meals or as part of the extended entertainment packages, which include attending cultural or sporting events. Engaging in these types of activities enables organization to build personal relationships between individuals that translate into commercial relationships; they can also help resolve conflicts and also management change (Chetwynd, 2000; Hughes, 2000; cited in Lugosi, 2014). It is possible to argue that mobilizing hospitality and establishing host- guest relations, which facilitates interdependency, generate affective relationships and invites reciprocities, is a form of strategic enchantment. In accepting corporate hospitality, external stakeholders assume the role of guest, which entails some willingness to conform to expectations of the role; becoming a guest also acknowledges the status and position of the host. 
Commercial practitioners offer commentary on the significance and changing nature of corporate hospitality (Quainton, 2009; cited in Lugosi, 2014), but there have been limited attempts to provide academic analysis of corporate hospitality (Roger, 2003; cited in Lugosi, 2014). More importantly, there is a dearth of social scientific research into the way corporate hospitality is mobilized by organizations to create ongoing relationships between them and various stakeholders.

Asymmetric hospitality: An alternative interpretation of the management and employee activities is that they are attempts to blur the divide between colleagues and to reconstruct the organization as a hospitable space. These studies also highlight another key aspect of hospitable spaces and relationships - obligations too participate and reciprocate. Such transactions mobilize asymmetric hospitalities (Lugosi, 2009), where relationships are no longer simply between individuals who give and receive, but between individuals and broader entities i.e. organizations and the various social networks entangled in their existence. Food is one part of these transactions, but the broader and more significant issue is how hospitable gestures and the instrumental deployment of hospitality create obligations and reaffirms specific power relations. Hospitality can thus be thought of as an instrument of organizational entrenchment - a set of mechanisms and practices through which organizational cultures, norms and values are (re)produced. Gestures of hospitality may appear altruistic, but it is important to question the conditions and reciprocities mobilized in and by such transactions within organizational contexts. Re-examining food related organizational phenomena through notions of hospitality thus helps to understand them more broadly, while also conceptualizing the ongoing dynamics of the relationships between individuals (Lugosi, 2014).

Critical hospitality: Bell (2009) has advocated that hospitality is not limited on 'calculative hosting' (the cynical performance of hospitality laid on for the sole purpose of getting paid or getting rich) and 'calculative guesting' (whereby guests expect certain levels of service or servility simply because they are buying it, and the whole beauty of pure, open, unquestioning hospitality relationship is sullied and spoiled by being bought and sold). This scholar has proposed that one should go through 'critical' hospitality in which the emphasis has been given on the issue of labor relationship which is not only essential but also it is quintessential for understanding emotional labor to which Bell has coined the term 'critical turn'.

Mobile hospitality: A contribution in Bell (2007a, \& 2007b), as summarized in Lynch el al.(2011), acts as a bridge between the social control/social exchange categorization. Bell has employed simple but far-reaching definition of hospitality as 'welcome' and conceives of form of mobile hospitality that is the heart of human relations and confirms to the idea of hospitality as a social ethic. Bell (2007a, \& 2007b) has proposed the idea of diurnal 'moments' of hospitality predicated upon 
interactions between host and guests in city spaces, such as commuting to work, mega events and hospitality, or every day urban hospitableness. Thus one can conceive of a mobile hospitality that transcends spatial association with building.

Genuine hospitality: A genuine hospitality, according to Lashley et al. (2007), is a form of hospitality in which guests wish to experience pure form of services. It enables the study of hospitality through the meanings associated with it by the various participants in hospitality transactions. The experiences of being a guest in small hotels and guest houses provides insights into the use of public and private spaces in the 'commercial home sector' (Lynch, 2005; cited in Lashley et al., 2007). Guests often choose this form of accommodation because they wish to experience 'genuine hospitality' with a 'real family', while hosts frequently want to maintain their own private space which is excluded from their own private space which is excluded from their paying guests (Lashley et al., 2007). Fisher's (1987) study in Dolpo, one of the Himalayan districts of Nepal, shows how Tarangpurian people offer genuine hospitality on the occasion of feast. As he observed... a rich man will spend more for the celebration of his first son's first haircut than a poor man. He will serve rice instead of Chinu millet and his supply of distilled liquor will outlast the capacity of his guest to absorb it. Such an occasion will be a burden for a poor man, even if he substitutes Chinu millet for rice, beer for liquor and so on. In order to justify this the above mentioned facts, Fisher (1987) has quoted the local proverb which is as follows: Ista nahune manche kano, dhan nahune manche sano. A man without friends is blind in one eye, a man without wealth is small. Wealth is sought not so that a man can eat better, but so that he may feed others better. This desire to provide high-grade hospitality, which is not peculiar to the Magars of Tarangpur (pseudonym).

Official hospitality: Though Telfer (2000) does not seem keen interested to elaborate on official hospitality, has highlighted on its existence. As this scholar has explained that there is an establishment of official relationship between the host and guest. According to this scholar, official can carry out official duties of hospitality in the same friendly spirit in which they might entertain those in their circle, and when they are thought of as hospitable it is because they do this. As it is assumed that hospitable official can be regarded as extending their circle to include those they have an official duty to entertain.

Academic hospitality: This is another type of hospitality coined by Phipps and Barnett (2007). Academic hospitality takes and makes many forms. It takes material form in the hosting of academics and academic travelers. It takes epistemological form in the translation of academic work into other languages and it takes touristic form through welcome and generosity with which academic visitors are received. In each of these four forms (in material form, in epistemological form, in linguistic form, and in touristic form) academic hospitality involves the modes of what we 
might term both hosting and guesting. Both of these modes place different demands upon the academic

Intellectual hospitality: The term 'intellectual hospitality' first used by Kaufman (2001) and Bennett (2003). Later on, Germann Molz and Gibson (2007) applied it in the study of mobilizing hospitality. Their purpose of using it 'how the deployment of the concept of hospitality in one disciplinary content may provide insights in another. As Friese (2004; \& Still, 2004; in Germann Molz \& Gibson, 2007) argues 'what is at stake is not only the thinking of hospitality, but thinking as hospitality. In the able hands of scholars, the cultural, commercial, philosophical, political, ethical and social dimensions of hospitality have been subjected rigorous debate.

Linguistic hospitality: Ricoeur (1996; cited in Phipps \& Barnett, 2007) holds out translation as a model of linguistic hospitality [l'hospitalitelangagiere] that works within the limits of what is possible. This type of hospitality is closely associated with academic hospitality, although it has its own characters and relations in translation and expression on mode of culture in terms of hosting and guesting. In a world that is 'ineluctably polyglot' and where diversity persists, Ricoeur's translation ethos is designed 'to repeat at the cultural and spiritual level the gesture of linguistic hospitality In linguistic form, academic hospitality relates to the physical and practical challenges of communication. It may be that, with English as an increasingly accepted if contested lingua franca of academic life, the challenge is that of gaining literacy and fluency, in both written and spoken forms, in English. In addition, linguistic hospitality as academic hospitality relates to the need for a common discourse that allows those within fields of scholarly knowledge and activity to be able to communicate with each other with relative ease and with a common stock of referents, terms and concepts. Linguistic forms of academic hospitality also relate to the scholarly work of translation.

Embodied hospitality: Lynch et al. (2011) have pursued an embodied practice that engages multiple senses. According to them, food, drink and accommodations and other forms of consumption have important implications for understanding the embodied performance of hospitality. Hospitality is offered to and by embodied subjects. The power relations embedded in the hospitality encounter are often negotiated around embodied markers of difference, such as race, class, gender, sexuality and age, which intersect to shape the practice of hospitality (or hostility) in distinct ways. Furthermore, hospitality may be quite literally embodied in the case of organ of tissue donation. Hospitality implies a politics of comfort that applies not only to the host's and guest's ontological security but also to their embodies wellbeing (Lynch et al., 2011).

Divine hospitality: Boersma (2003) has shown that there is another type of 
hospitality. It is a hospitality that will be realized in the internal kingdom of God. In other words, unlike Derrida's pure hospitality, Ireneus's eschatological hospitality is based on divine transcendence and divine hospitality and assumes a future point at which this absolute eschatological hospitality will be realized.

Open hospitality: The notion of open hospitality has been coined by Burgess (1982). While writing about cultural continuity and change in the context of highlighting the importance of cultural hospitality, Burgess (1982) focused on continuity of primitive culture still existing in different parts of the world and also it is evident and so he writes, "Precipitated by the attribution of mystical powers to unknown strangers or feelings of mutual support when travelling themselves in hostile environments, heads of household and tribal leaders offered open hospitality to travelers and all who requested it" (Burgess, 1982). In order to justify his statement, Burgess (1982) links with the Latin hostis and Greek Ksenos meaning stranger and guest.

Personal Hospitality: While the house has connotations of a private, personal hospitality, the hotel represents a public, commodified experience of hospitality subject to the logic of economic exchange. In contrast, the fortress signals defensive nationalism, with strong and secure borders, inhospitable rather than hospitable. Entering these spaces will depend on the different imperatives which regulate them -- the political (fortress), ethical (house), and commercial (hotel) forms of hospitality (Gibson, 2006).

Intra-tribal hospitality: Intra-tribal hospitality in largely focused on reciprocity as different families in the tribe provide feasting in the understanding that they will be guests of their guest on another occasion. This has been studied by Cole (2007) on Ngadh tribe of Indonesia.

Conditional and Unconditional Hospitality: Both the conditional and unconditional hospitality are the products of Kant and Derrida. As far as the conditional hospitality is concerned, Kant, in his book entitled Perpetual Peace. A Philosophic Sketch, states the law of world citizenship shall be limited to conditions a universal hospitality; His idea is very much related with the concept of conflict and peace. Hospitality for Kant means...the right of a stranger is not to be treated as an enemy when he arrives to the land of another. One may refuse to receive him when this can be done without causing his destruction; but, so long as he peacefully occupies his place, one may not treat him with hospitality. Kant goes on to write that hospitality is... not the right to be a permanent visitor... a special beneficent agreement would be needed in order to give an outsider a right to become a fellow inhabitant for a certain length of time. It is only a right of temporary sojourn, a right to associate which all men have. They have it by virtue of their common possession of the surface of the earth, where as a globe, they cannot infinitely disperse and hence 
must tolerate the presence of each other.

For Derrida there is always a tension between the limits of conditional hospitality and an infinite unconditional hospitality. Derrida (2000b; cited in Laachir, 2007) has argued that hostis reveals a strange crossing between enemy and host. This is due to the troubling analogy in their common origin between hostis as host and hostis as enemy and thus between hospitality and hostility or what Derrida calls hostipitality: hospitality carrying within it the danger of hostility. The distinction introduced in Derrida's works between, on the one hand, unconditional hospitality or 'absolute desire for hospitality' and on the other, conditional hospitality or the rights and duties that condition hospitality ('a law, a conditional ethics, a politics) is not a distinction that 'paralyses' hospitality (Laachir, 2007). To keep alive the aporia between ethics (the law of hospitality) and politics (the laws of hospitality) is to keep political laws and regulations open to new changes and circumstances and to keep alive the fact that hospitality is always inhabited by hostility. It is the question of intervening in the conditional hospitality in the name of unconditional, an intervention that, though surrounded by contradictions and aporias, recognize the need of 'perverting' the laws for the sake of 'perfecting' them.

The distinction introduced in Derrida's works between, on the one hand, unconditional hospitality or 'absolute desire for hospitality' and on the other, conditional hospitality or the rights and duties that condition hospitality ('a law, a conditional ethics, a politics) is not a distinction that 'paralyses' hospitality (Laachir, 2007). To keep alive the aporia between ethics (the law of hospitality) and politics (the laws of hospitality) is to keep political laws and regulations open to new changes and circumstances and to keep alive the fact that hospitality is always inhabited by hostility. It is the question of intervening in the conditional hospitality in the name of unconditional, an intervention that, though surrounded by contradictions and aporias, recognizes the need of 'perverting' the laws for the sake of 'perfecting' them.

Universal hospitality: Humans inhabit a geographically limited planet and it is our natural destiny to come into contact with one another. This 'natural law' of shared residence on the earth surface assumes a 'cosmopolitan right' to travel and encounter each other under various auspices. This right is conditioned by the law of 'universal hospitality' which ensures the rights and duties associated with the moment of foreigners around the world: the right to travel and be received in other land without hospitality, and a duty to not use once travels as a means of exploitation or oppression (Germann Molz, \& Gibson, 2007). Kant (1957; cited in Lachir, 2007, p. 179) has envisaged universal hospitality as a condition of perpetual peace and world citizenship. It is only through hospitality that humanity can gradually be brought closer to a constitution establishing world citizenship and thus perpetual peace. Kant has dismissed hospitality as philanthropy and insists on its being a right 
or a 'natural law'. Kant's notion of universal hospitality and cosmopolitan right to address contemporary concerns, especially around issues of migration, asylum and citizenship. Derrida has explained that because Kant's notion of hospitality relies on condition of reciprocity, duties and obligations between people and nation-states it delimits rather than opens up borders and possibilities. Jacques Derrida admonishes that Kant's hospitality is only juridical and political: it grants only the right of temporary sojourn and not the right of residence; it concerns only the citizens of state (Derrida, 1999: 87; cited in Germann Molz \& Gibson, 2007, p. 4). Kant's ideas on cosmopolitanism and world citizenship have been important in framing contemporary debates on hospitality (Lachir, 2007, p. 179).

Absolute hospitality: This type of hospitality is an independent form has been coined by Derrida (2004; cited in O'Dell, 2007). This concept may shed light on social relations and encounters between strangers in various contexts. In this regard, O'Dell has followed the view of Derrida and claimed, "It should be noted that the form of hospitality interrogated in the chapter is characterized by a situation in which the guest/host relationship is bound by commercialized process of exchange. It is, in other words, a phenomenon limited and controlled by contextually defined laws (in the plural) that place obligations upon both the guest and the host. As a result, it never approaches the phenomenon that Derrida called 'absolute hospitality" (p. 104).

Civic hospitality: This type of hospitality has been studied by O'Gorman (2007). In course of describing this type of hospitality O'Gorman has followed the laws of Plato. In his "Laws" and mentioned four types of stranger/guest from abroad who are to be welcomed but treated differently, according to their purpose, rank and status. They may be summarized as Merchant on trade or business: who is to be received by the officials in charge at the markets, harbors, public buildings, outside of the city. Cultural visitors to view artistic achievements, including musical performances: who is to be received at temples where friendly accommodations are to be provided? Civic dignitary on public business: who is to be received at civic receptions and by the generals and public officials? The relationship is formal and business like and the official with whom the dignitary lodges is responsible for their care and conduct. Occasional high-status cultural visitor, who must be over 50 years of age, to view art objects, or to exhibit such objects: who is to be welcomed as a visitor of the rich and wise? Plato also indicated that there should be conformity within the 'Laws' for all guests/strangers from abroad, and the 'Laws' also apply when sending out the state's own citizens to other states.

The above mentioned many different types of hospitality seem to be overlapped in many contexts. There are few types of hospitality which are independent forms whose nature and scopes are very important. 


\section{Hospitality and Neologism}

Eating out has become a central part of 'experience economy' of cities (Pine \& Gilmore, 1998) as Finkelstein (1999; cited in Bell, 2007) has renamed eating out using the neologism 'foodatainment' to emphasize that it is about so much more than just eating. Foodatainment is regularly conscripted into the place promotion techniques so central to regeneration, with parts of the city particularly 'sold' on the basis of the food on offer - especially, perhaps, in the case of 'ethnic' foods, as in Chinatowns (Bell, 2004).

The form of foodatainment emphasized by Finkelstein is referred to as highstyle restaurant dining and is also accompanied by other forms of food-related entertainments, from the pleasures of wandering a sumptuous food hall or deli, visually consuming the produce on display, to the equally pleasurable but more every day experiences of coffee shops, take-away and local bars, in which different forms of hospitality and commensality are enacted. And, of course, the experience economy of cities or districts also has parallels in what might be called 'drinkatainment' the production of themed bars and pubs, ranging from the staged authenticity of Irish theme pubs to Soviet styled vodka bars (Williams,2000; cited in Bell,2007:91). Both foodatainment and drinkatainment have become cornerstones of the urban regeneration script, which increasingly emphasizes the value of the night-time economy to cities seeking to improve their fortunes (Chatterton, \& Hollands, 2003; cited in Bell, 2007, p. 91). However, the ways in which districts utilize foodatainment and drinkatainment produce radically different kinds of hospitality space and experience. For Lashley et al. (2007:181) another neologism is 'hospitaintment' which denotes all.

\section{Hospitality and Gender}

Women bring a set of competences to their management positions that successful hospitality organizations require. Numerous studies confirm that there are management style differences between men and women (Kolb,1990;Pounder \& Coleman,2002). Typical of a feminine style are competences such as building consensus, effective listening, team building, inclusive communication and valuing diversity. Women are kiss directive and more empowering. They value relationships, fostering collaborative decision making and creative problem solving. Women also tend to provide more feedback to employees than do their male counterparts (Burke \& Collins, 200; Oshagbemi \& Gill,2002; cited in Brownell, 2013:161).

Elsewhere (Veijola \& Jokinen, 2005, 2008) we have adopted a view on gender as a contingent act, not unrehearsed but not predetermined either, and based on the notion of habit (Bourdieu, 1990) and performative acts (Butler,1990). Combining this notion of gender with the framework of new work described earlier, we suggested 
that the Western world is turning into a hostessing society. In other words, rather than world having become increasingly (masculine ) and mobile (see Urry, 2000; Hannam,2008), the world has started to host and, even more interestingly, to hostess. 'Hostessing is a qualification, competence, skill, appearance, offering and vocation that new working life requires from both women and men; as a concept of doing and action, instead of structure and actor, it evokes a gender aspect but does not glue it to individuals like the noun of a 'hostess' would do (Veijola \& Jekinen, 2008:170).It is 'a vital, albeit- often for those empowered by male gender- transparent, element in the world economy where gender is the reproduce in the interplay between contingency and habit' (Veijola \& Jokinen, 2008:177; cited in Veijola, 2010:115).

\section{Tourism and Hospitality}

The term 'tourism' appeared in 1811 AD (Kunwar, 2012). The various derivations of what we now call 'tourism' revolve around the idea of circular movement. The term comes from the Latin tornare to turn or to round off and tornus wheel - a circular movement relating to change of residence (Mieczkowski, 1990; Smith, 1990; in Mill, 2008: 98). The French word tour suggesting circular tower and circular travel with a return to the point of departure leads to tourisme in French, tourismo in Italian, tourismus in German, the English 'tourism' and the Russian turizm (Mieczkowski, 1990: 21; cited in Mill, 2008, p. 98.)

Franklin (2003, p. 100) summarizes various definitions as follows: 'the temporary movement of people to destinations outside their normal places of work and residence, the activities undertaken during their stay in those destinations and the facilities created to cater to their need' (Franklin, 2003, pp. 27-28; Mathieson \& Wall, 1982, p.1; in Kunwar, 2012, p. 11).

Franklin holistically identifies the characteristics of modern tourism as follows (Franklin, 2003, p. 101):

- It is derived from the condition and experience of life in modernity and is not an escape from it;

- Modernity, in turn, is about the permanence of novelty and not an escape to it;

- It is more than travel - it is about accessing novelty and the modern world;

- It is consumerism;

- The framework for tourism has been influenced by nationalism, nation states and latterly by cities and regions;

- It is more than a visual experience and certainly more than rest, relaxation and pleasure. It exists within a political and moral context; and

- It is way of accessing the world and, increasingly, our place within it. 
Is there any relationship between 'tourism' and 'hospitality'? It is common, though incorrect to use the term hospitality industry interchangeably with tourism or tourism industry. The term is also used to refer the various types of lodging, accommodation that are part of tourism (Grottola, 1988). To many, 'tourism' involves the people while hospitality is concerned with overnight stays (Bushwell \& Williams, 2003). One the deeper level the 'tourist process' can be thought of consisting of three elements of travel, accommodation and participation in activities at the destination. Others would be the social economic and environmental impacts resulting from these elements (Bushwell \& Williams, 2003; cited in Mill, 2008, p. 104).

The diversity of the hospitality sector relates to the difficulty in developing a straight forward definition (Ninemeier \& Perdue, 2005; cited in Ottenbacher et al., 2009). The hospitality industry is often associated with the tourism industry but most people relate it to hotels and restaurants (Powers \& Barrows, 2006). According to Lashley (2001), educational institutions and industrial organizations in Englishspeaking countries employed the term hospitality to define a group of service firms that were related to the provision of food, drink and accommodation. Indeed, UK academics (Brotherton, 1999; Jones \& Lockwood, 2000; Lashley, 2001) have argued that the hospitality industry consists of activities that were called hotels and catering in earlier times.

In contrast, the US academics suggest that hospitality should be defined in a broader perspective. Several definitions combine the hospitality and tourism fields under the umbrella of travel and tourism (e.g., Walker, 2004) and define travel, lodging, food service, clubs, gaming, attractions, entertainment, and recreation as sectors of the hospitality field (Nykiel, 2005; Ottenbacher et al., 2009). Earlier, Powers (1992) and Ottenbacher et al.(2009) described hospitality as primarily consisting of hotels and restaurants, and tourism-travel as an affiliated industry. The scholars have explained that the term hospitality comes from medieval "hospice" meaning "house of rest" for travelers and pilgrims. Later, Walker (2004; Ottenbacher et al., 2009) identified four major areas of the hospitality field as travel, lodging food service and recreation.

To the current hospitality situation, one can identify hospitality as a field (not an industry) comprising of six separate industries, such as lodging, food service, travel, conventions, leisure and attractions. Gee, Makens and Choy (1997) have classified travel-related industries into three categories. Category 1 includes direct providers of services, such hotels, restaurants, travel agents, airlines, and ground transportation. Category 2 includes support services that provide direct or indirect service to a traveler (contract food service, tour organizers, travel publications, etc.). Category 3 includes tourism development agencies or organizations such as government agencies, financial institutions, real estate developers, and so on. Thus, Gee et al. 
(1997) have considered category 1 as the primary supporters of the travel industry followed by the Categories 2 and 3. This understanding is consistent with many other classifications of the hospitality-tourism field.

Interestingly, the US Department of Commerce, Standard Industrial Classification (SIC) System (SIC, 2007) has provided a very distinct alterative using output as the dependent measure in classifying industries. Industries are separated based on the differences in their primary output products. For example, 4724 represents Travel Agencies, and 4725 represents Travel Operators; 5812 reflect Primarily Eating Establishments and 5813 reflect Primarily Drinking Establishments (Ottenbacher et al., 2009, p. 266).

In social sciences, hospitality is a heavily marginalized field. Hospitality needs emancipatory knowledge and therefore a critical theory perspective. In the field of tourism, business and management, hospitality is observed only through the commercial relationships between the hosts and the guests, with the main theme being operational efficiency. Looking through a hospitality social lens, tourism is actually a component of hospitality; it is an industrial and commercial part. However, looking from the strict commercial perspective, tourism is a broader umbrella term and hospitality is a part of the tourism concept. Tourism is about destinations, whether a city, a part of the city, a region, a geographical area, a national park, a country, a continent, etc. Hospitality concerns hotels, restaurants and entertainment facilities. Tourism concerns a total destination, a macro perspective, and an industry. In commercial term this is correct. However, looking from a slightly different position, from a position of researching the relationships between people in society, host guest relationship, a core of hospitality, one realizes that the meaning of hospitality is much more than tourism (Causevic \& Lynch, 2009).

Brotherton (2002) has examined whether or not hospitality exists as a separate entity from tourism, travel or leisure. He indicated that hospitality can, in fact, exist without tourism (people enjoying a meal while shopping), travel (in a local pub) or leisure (business man taking client a lunch). Tourism in other hand cannot exist without travel but can without leisure (business tourism). Travel can however exist without tourism or leisure (business travel). Leisure can also exist independent of hospitality - reading books at home -tourism and/or travel. Thus, he concludes, hospitality can be distinguished from tourism, travel and leisure. Further hospitality, leisure and travel are all concepts distinct and discrete from each other. Although travel is seen as necessary condition for tourism to occur other things- motivation time, money - are also required (Mill, 2008).

One way to view the interrelationship is to examine the way academics have organized tourism and hospitality at the university level. There are three primary 
models that assist in understanding the philosophical bases of tourism and hospitality academic programs (Chen \& Groves, 1999; cited in Mill, 2008). The first views tourism and hospitality as mutually inclusive. In this model both are independent with some areas of overlap. While the identity of each discipline is recognized, the common overlap areas include the pieces that can be transferred from one to other. Tourism concentrates on the impact of marketing studies, economic, environmental and social impact studies. Hospitality is concerned with service, marketing, and management of travel, hotels, commercial recreation and other leisure business.

The second views hospitality on a superior position to tourism where hospitality is a superior position to tourism where hospitality is a primary driving force as a service component to other industries (Chen, Groves 1999; cited in Mill, 2008, p. 104). This model views hospitality as service based (hotels, restaurants, casinos etc) and tourism synonymous with travel sector. The third model views tourism as superior to hospitality. Tourism is viewed as important economic activity that express for some concern for the impact of development on social, cultural and ecological fabric of destination. The hospitality industry develops to service tourism because of tourism's great economic importance. Its role is in the development of infrastructure to support tourism.

\section{Conclusions}

The study of hospitality as a human phenomenona or in other word a social phenomenon directly deals and essentially involves the relationship between host and guest. From the social context, hospitality can be referred to as the act of being hospitable while from the commercial perspective hospitality can also be regarded as a sub-sector of the service industry. Ottenbacher et al. (2009) have contended that hospitality is still considered as a relatively new research discipline with no consensus on its definition and concepts although it was claimed to be the world's largest industry. This statement would be the answer of what is hospitality?

UK hospitality research, both qualitatively and quantitatively, is at best static and even in decline. This may be due to factors that academics might like to think of as outside their control - declining student numbers, marginalization within their institutions, and lack of external funding, failure to attract $\mathrm{PhD}$ students, lack of industry support. But evidence from other countries suggests that these factors have not affected hospitality research. Indeed, Pizam (2003; cited in Jones, 2004) has stated that hospitality educators are among the top academics in many universities around the world (sic) and hospitality students are as intelligent and academically adept as students in the science, humanities, business and arts...our field is sufficiently challenging to attract the best young minds of our generation.

In the natural sciences there have been many controversies between alternative 
schools of thoughts, perhaps most famously between creationist and Darwinists. Such debates require protagonists to sharpen their logic, develop their arguments and produce their evidence. Until recently, hospitality researchers and academics have tended to avoid controversy. Perhaps a sign of maturity would be to welcome it? "A wider hospitality perspective could facilitate an exploration of trans-historical and cross-national and /or cultural studies of hospitality" (Brotherton, 1999, p. 171). It is suggested to conduct research on diplomatic hospitality, brothel hospitality, airlines hospitality, ethno-hospitality or rural hospitality, military hospitality, airport hospitality and hospitality at prison which will be inspiring subject for future researchers. This article will also inspire to the future researchers for studying on what Nepalese hospitality is.

Hospitality in Nepal

Atithi devo bhava

(Guest is equivalent to God)

\section{Acknowledgement}

First and foremost, I would like to express my sincere thanks to Dr. C.P. Rijal, an eminent scholar of Nepal, who without any hesitation checked this manuscript. Likewise, I would also like to thank to Tirtha Laxmi Maharjan, Usha Chand and Anub Bhandari of CPDF who helped me in managing this work. They are Madav Raj Tripathee of IST College, Ranjeeta Shrestha of NCM, Merina Lama of GATE College, Bibek Raj Kunwar (studying MBA Hospitality in America) and Saurav Raj Kunwar who also deserve acknowledgement for their help in preparing this research paper.

\section{References}

Airey, D. \& Tribe,J.(2000). Education for hospitality In Lashley, C. \& Morrison, R.(eds.) In Search of Hospitality: Theoretical Perspectives and Debates(pp.255-275), Oxford: Butterworth/ Heinemann.

Aramberri, J. (2001). The host should get lost paradigms in the tourism theory. Annals of Tourism Research, 28 (3), 738-761.

Ariffin, A. A. M., Magzhi, A. \& Aziz, N. (2011). Understanding hotel hospitality and differences between local and foreign guests. International Review of Research Papers, 7(1), 340-349.

Bell, D. (2009). Tourism and hospitality. In Jamal, T.\& Robinson, M. (eds.). The Sage Handbook of Tourism Studies(pp.19-34), London: Sage.

Bell, D. (2007a). Moments of hospitality. In Germann Molz, J. \& Gibson, S. (eds.) Mobilizing Hospitality: The Ethics of Social Relations in a Mobile World. Aldershot: Ashgate. 
Bell,D.(2007b). Hospitality and urban regeneration. In Lashley, C., Lynch, P. \& Morrison, A. (eds) Hospitality A Social Lens (pp.89-99), Amsterdam: Elsevier.

Boersma, H. (2003). Irenaeus, Derrida and hospitality: on the eschatological overcoming of violence. Modern Theology, 19(2), 163-180.

Brotherton, B. (2013). Hospitality and hospitality management. In Wood, R. C. (ed.) Key Concepts in Hospitality Management. London: Sage Publishing.

Brotherton, B. (1999). Towards a definitive View of the Nature of Hospitality and Hospitality Management. International Journal of Contemporary Hospitality Management, 11 (4), 165-173.

Brotherton, B. \& Wood, R.C.(2000). Defining hospitality and hospitality management In Lashley, C. \& Morrison, A. (eds.) In Search of Hospitality-Theoretical Perspectives and Debates (pp.134-156), Oxford: Butterworth/Heinermann.

Brotherton, B. \& Wood, R. C. (eds.). (2008). The Sage Handbook of Hospitality Management, London: Sage.

Brotherton, B. \& Wood, R. C. (2008). The nature and meanings of hospitality. In Brotherton, B. \& Wood, R. C. (eds.). The Sage Handbook of Hospitality Management, (pp. 36-61). London: SAGE.

Brownell, J. (2013).Women, gender and hospitality employment. In Wood, R.C. (ed.) Key Concepts in Hospitality Management(pp.157-162), London: Sage.

Burgess, J. (1982). Perspectives on gift exchange and hospitable behavior. International Journal of Hospitality Management, 1(1), 49-57.

Chung-Herrera, B. G., Enz, C. A. \& Lankau, M. J. (2003). Grooming future hospitality leaders: a competencies model. Cornell Hotel Restaurant Administration Quarterly, 44(3), 17-25.

Cole, S. (2007). Hospitality and tourism in Ngadha: an ethnographic exploration. Hospitality a Social Lens (pp.61-72)., Amsterdam: Elsevier.

Cohen, E. \& Cohen, S. (2012). Current sociological theories and issues in tourism. Annals of Tourism Research, 39(4), 2177-2202.

Cresswell, T. (2007). Hospitality and migrant memory in Maxwell Street Chicago. In Germann Molz, J. \& Gibson, S. (eds.) Mobilizing Hospitality (pp.47-64), Aldershot: Ashgate.

Dikeç, M., Clarke, N. \& Barnett, C. (eds.). (2009). Extending Hospitality: Giving Space, Taking time. Edinburg: Edinberg University Press.

Fine, G.A. (2008). Kitchens: the culture of restaurant work (update with new preface), Burkeley: University of California Press. 
Fisher, J. F. (1987). Trans-Himalayan Traders: Economy, Society, and Culture in Northwest Nepal, Delhi: Motilal Banarasidas.

Franklin, A. (2003). Tourism: an introduction. London: Sage Publications.

Fridgen, J. D. (1996) Tourism and the Hospitality Industry, Educational Institute American Hotel and Motel Associations.

Friese, H. (2004). Spaces of hospitality. Angelaki: Journal of the Theoretical Humanities, 9(2), 67-79.

Gee, C. Y., Makens, J. C.\& Choy, D. J. (1997). The Travel Industry. New York: John Wiley.

Germann Molz, J. \& Gibson, S. (2007). Mobilizing Hospitality: The Ethics of Social Relations in a Mobile World. Aldershot: Ashgate.

Gibson, S. (2003). Accommodating strangers: British hospitality and the asylum hotel debate. Journal of Cultural Research, 7 (4), 367-386.

Gibson, S. (2006). The hotel business is about strangers' border politics and hospitable spaces in Stephen Frear's dirty pretty things. Third Text, 24 (6), 693-703.

Gibson, S. (2007). 'Abusing our hospitality: inhospitableness and the politics of deterrence: in Germann Molz, J. \& Gibson, S. (eds.) Mobilizing Hospitality (pp. 159-176), Aldershot: Ashgate.

Harrison, D. \& Lugosi, P. (2013). Tourism culture(s): the hospitality dimension. Tourism Recreation Research, 38(3), 269-279.

Haywood, K. M. (1983). Assessing the quality of hospitality services. International Journal of Hospitality Management, 2(4), 165-177.

Hepple, J., Kipps, M., \& Thompson, J. (1990). The concept and an evaluation of its applicability to the experience of hospitality patience. International Journal of Hospitality Management, 9(4), 305-318.

Hochschild, A. R. (1983). The Managed Heart Commercialization of Human Feeling. Berkeley: University of California Press.

Jones, P. (2004). Finding the hospitality industry? Or finding hospitality schools of thought? Journal of Hospitality, Leisure, Sport and Tourism Education, 3(1), 33-45.

Jones, P. (1998). (ed.). Hospitality management. International Journal of Hospitality Management, 17, 105-110.

Jones, P. \& Lockwood, A. (1995). Hospitality operating systems. International Journal of Contemporary Hospitality Management, 7(5), 17-20.

Kattara, H. S. Iraqj, M. \& Hewedi, M. (2004). Tourism and hospitality research experience: a highlight of tourism and hospitality research issues in Egyptian 
higher education. Journal of Teaching in Travel and Tourism, 4(2), 1-7.

Kay, C. \& Russette, J. (2000). Hospitality - management competencies. Cornell Hotel and Restaurant Administration Quarterly, 52-63.

Keung, S. W. C. (2000). Tourist's perceptions of hotel frontline employees' questionable job related behavior. Tourism Management, 21, 121-134.

Kim, H. J. (2007). Hotel service providers' emotional labor: the antecedents and effects on burnout. International Journal of Hospitality Management, 27, 151-161.

King, C. A. (1995). What is hospitality? International Journal of Hospitality Management, 14(3/4), 219-234.

Korstanje, M. E. \& Tarlow, P. (2012). Being lost: tourism, risk and vulnerability in the post-9/11 entertainment industry. Journal of Tourism and Cultural Change, 10(1), 22-33.

Kunwar, R. R. (2012). Tourists and Tourism Science and Industry Interface. Kathmandu: Ganga Sen (Kunwar).

Laachir, K. (2007). Hospitality and the limitations of the national. In Germann, M. J., \& Gibson, S. (eds.) Mobilizing Hospitality: The Ethics of Social Relations in a Mobile World (pp.177-192),Aldershot: ASHGATE.

Lashley, C. (2000). Towards a theoretical understanding. In Lashley, C., \& Morrison, A. (eds.) In Search of Hospitality Theoretical Perspectives and Debates (pp.1-17), Oxford: Butterworth-Heinemann.

Lashley, C., Lynch, P., \& Morrison, A. (eds.). (2007). Ways of knowing hospitality. Hospitality: A Social Lens, 173-191. Amsterdam: Elsevier

Lashley, C., Lynch, P., \& Morrison, A. (eds.). (2007). Hospitality A Social Lens. Amsterdam: Elsevier.

Lashley, C., \& Morrison, A. (eds.)(2000). In Search of Hospitality Theoretical Perspectives and Debate. Oxford: Butterworth \& Heinemann.

Leiper, N.(2000). An emerging discipline. Annals of Tourism Research,27(3):805-809.

Lugosi, P. L. (2014). Hospitality and organizations: enchantment, entrenchment and reconfiguration. Hospitality and Society, 4(1).

Lugosi, P. L. (2009). Ethnography, ethnographers and hospitality research: communities, tensions and affiliations. Tourism and Hospitality Planning and Development, 6(2), 95-107.

Lugosi, P. L. (2009). The production of hospitable space: commercial propositions and consumer co-creation in a bar operation. Space and Culture, 12(4), 396-411. 
Lugosi, P. L. (2008). Hospitality spaces, hospitable moments: consumers encounters and affective experiences in commercial settings. Journal of Food Service, 19, 139149.

Lugosi, P., Lynch, P., \& Morrison, A. (2009). Critical hospitality management research. The Industries Journal, 29(10).

Lynch, P. A. (2005). Sociological Impression in a Hospitality Context. Annals of Tourism Research, 32(3): 527-548.

Lynch, P., Di-Domenico, M. L., \& Sweeney, M. (2007). Resident hosts and mobile strangers: temporary exchanges within the topography of the commercial home. In Germann, M. J., \& Gibson, S. (eds.). Mobilizing Hospitality (pp. 121-144), Aldershot: Ashgate.

Lynch, P., Germann, M. J., McIntosh, A., Lugosi, P., \& Lashley, C. (2011). Theorizing hospitality. Hospitality and Society, 1(1), 3-24.

Lynch, P., \& Macwhannell, D. (2000). Home and commercialized hospitality. In Lashley, C. \& Morrison, A. (eds.) In Search of Hospitality (pp.100-144), Oxford: Butterworth/Heinemann.

March, C. S. (1987). Hospitality, women, and the efficacy of beer. Food and Food Ways, I:351-387.

McCabe, S. \& Marson, D. (2006). Tourist constructions and consumptions of space: place, modernity and meaning. In Burns, P. M. \& Novelli, M. (eds.) Tourism and Social Identities: Global Frameworks and Local Realities, 91-110. Amsterdam: Elsevier.

McIntosh, A. J., Lynch, P. \& Sweeney, M. (2010). My home in my castle: defiance of the commercial homestay home in tourism. Journal of Travel Research, $X X(X)$, $1-11$.

Mill, R. C. (2008). The Inter-Relationships between Leisure, Recreation, Tourism and Hospitality. In Brotherton, B. \& Wood, R. C. (eds). The Sage Handbook of Hospitality Management (pp.90-106), London: Sage.

Morrison, A. \& O'Gorman, K. (2008). Hospitality studies and hospitality management: a symbiotic management. International Journal of Hospitality Management, 27, 214-221.

Muhlmann, W. (1932). Hospitality. In Seligman, E. (ed.). Encyclopedia of the Social Sciences, 7, New York: Macmillan.

Munsters, W. (2010). The cultural destination experience audit applied to the touristhistoric city. In Richard, G., \& Munsters, W. (eds.). Cultural Tourism Research Methods(pp.52-60), Wallingford: Cabi. 
Nailon, P. (1982). Theory in hospitality management. International Journal of Hospitality Management, 1(3), 135-143.

O’Dell, T. (2007). Hospitality, kinesthesis and health: Swedish spas and the market for well-being. In Germann Molz, J. \& Gibson, S. (eds.). Mobilizing Hospitality: the ethics of Social Relation in a Mobile World (pp.103-120), Aldershot: Ashgate.

O'Gorman, K. D. (2007). Dimensions of hospitality exploring ancient origins. In Lashley, C. Lynch, P., \& Morrison, A. (eds.). Hospitality A Social Lens(pp.17-32), Amsterdam: Elsevier.

O'Gorman, K. D. (2010). The Origins of Hospitality and Tourism, Oxford: Goodfellow Publishers.

Ottenbacher, M., Harrington, R., \& Parsa, H. G. (2009). Defining the hospitality discipline: a discussion of pedagogical and research implications. Journal of Hospitality's Tourism Research, 35(3), 363-383.

Page, S. (2003). Review. In search of hospitality: theoretical perspectives and debates. Tourism Management, 24, 719-728.

Phipps, A.\& Barnett, P. (2007). Academic hospitality; Arts and Humanities in Higher Education, 6(3), 237-254.

Picard, D. (2013). Cosmopolitanism and hospitality. In Smith, M. \& Richards, G. (eds.). The Routledge Handbook of Cultural Tourism, 164-171. London: Routledge.

Pine, B.J. II \& Gilmore, J.H. (1998). Welcome to experience economy. Harvard Business Review, July-August, 97-105.

Reisinger, Y. (2009). International tourism: cultures and behavior. Amsterdam: Elsevior.

Reuland, R., Choudry, J. \& Fagel, A. (1985). Research in the field of hospitality. International Journal of Hospitality Management,4(4), 141-146.

Rijal, C.P. \& Ghimire, S. (2016), Prospects of Creating Memorable Experience in Nepalese Tourism and Hospitality Industry. Journal of Tourism and Hospitality Education, 6, 40-66.

Ritzer, G. (2007). Inhospitable hospitality? In Lashley, C., Lynch, P. L.\& Morrison, A. (eds.). Hospitality: A Social Lens (pp.129-139), Amsterdam: Elsevier.

Santich, B. (2007). Hospitality and gastronomy: natural allies. In Lashley, C., Lynch, P.\& Morrison, A. (eds.). Hospitality A Social Lens(pp.47-60), Amsterdam: Elsevier.

Selwyn, T. (2013). Hospitality. In Smith, M. \& Richards, G. (eds.) The Routledge Handbook of Cultural Tourism. London: Routledge.

Sheringham, C. \& Daruwalla, P. (2007). Transgressing hospitality: polarities and 
disordered relationships? In Lashley, C., Lynch, P. \& Morrison, A. (eds.). Hospitality: A Social Lens (pp.33-46), Amsterdam: Elsevier.

Sherlock, K. (2001). Revisiting the concept of hosts and guests. Tourist Studies, 1(3), 271-295.

Sims, R. (2009). Food, place and authenticity: local food and the sustainable tourism experience. Journal of Sustainable Tourism, 17(3), 321-336.

Slattery, P. (2002). Finding the hospitality industry. Journal of Hospitality, Leisure, Sport and Tourism Education,1(1),19-27.

Slattery, P. (2003). Finding the hospitality industry (Slattery's Reply to Brotherton). Journal of Hospitality, Leisure, Sport and Tourism Education.2(1): 119-120.

Smith, V. L. (ed.) (1989). Hosts and Guests: The Anthropology of Tourism. Philadelphia: University of Pennsylvania Press.

Stierand, M. B. (2013). Gastronomy and haute cuisine. In Wood, R. C. (ed.). Key Concepts in Hospitality Management. London: Sage.

Tauhari, V. (2006). Competencies for a career in the hospitality industry: an Indian perspective. International Journal of Contemporary Hospitality Management, 18(2), 123-134.

Taylor, S. \& Edgar, D. (1996). Hospitality research: the emperor's new clothes? International Journal of Hospitality Management, 15(3), 211-227.

Telfer, E. (2000). The philosophy of hospitableness. In Lashley, C., \& Morrison, A. (eds.). In Search of Hospitality, 38-55. Oxford: Butterworth Heinemann.

Thio, S. (2005). Understanding hospitality activities: social, private, and commercial domain. Journal Manajement Perhotelan, 1(1), 1-5.

Tolia-Kelly, D. P. (2013). Book review. Extending Hospitality: Giving Space and Taking Time. Edinburgh: Edinburgh University Press.

Tresidder, R. (2013). The marketing language of hospitality. GSTF Journal of Business Review, 3(1), 99-105.

Tribe,J.(1997). The indiscipline of tourism. Annals of Tourism Research,24(3),638-657.

Tribe,J.(2000). Undisciplined and Unsubstantiated. Annals of Tourism Research, 27(3), 809-813.

Tribe, J. (2004). Knowing about tourism: epistemological issue, In Phillimore, J., \& Goodson, L. (eds.). Qualitative Research in Tourism: Ontologies, Epistemologies, Methodologies, 46-62. London: Routledge.

Tunney, J. (2006). The ghost host community in the evolution of travel law in world 
trade contexts: a pragmatic cosmopolitan perspective. In Burns, P. M. \& Novelli, M. (eds.). Tourism and Social Identities: Global Frameworks and Local Realities, 61-78. Amsterdam: Elsevier.

Uriely, N. \& Reichel, A. (2000).Working tourists and their attitudes to hosts. Annals of Tourism Research, 27(2), 267-283.

van Keken, G. \& Go, F. (2006). Close encounters: the role of culinary tourism and festivals in positioning a region. In Burns, P. M. \& Novelli, M. (eds.) Tourism and Social Identities (pp. 49-60), Amsterdam: Elsevier.

Veijola, S.(2010). Gender as work in the tourism industry. Tourist Studies, 9(2):109126.

Walton, J. K. (2000). The hospitality trades: a social history. In Lashley, C., \& Morrison, A. (eds.). In Search of Hospitability (pp.56-76), Oxford: Butterworth/Heinemann.

Wharton,A.(2007). Commodifying space; hotels and pork bellies. In Lashley, C.,Lynch, P.\& Morrison, A. (eds.) Hospitality A Social Lens (pp.101-116), Amsterdam: Elsevier.

Wood, R. C. (ed.)(2013). Key Concepts in Hospitality Management. London: Sage.

Wood R. C. (2013). Hospitality management education. In Wood, R. C. (ed.) Key Concepts in Hospitality Management. London: Sage.

Wood, R. H. (1989). More alike than different: the culture of the restaurant industry. Cornell Hotel and Restaurant Administration Quarterly, 82-97.

Zlomislic, M. (2004). Conflict, tolerance and hospitality. The Philosopher, LXXXX 11: 2 . 